\title{
Coadsorption of a Monoclonal Antibody and Nonionic Surfactant at the SiO2/Water Interface
}

DOI:

10.1021/acsami.8b16832

\section{Document Version}

Accepted author manuscript

Link to publication record in Manchester Research Explorer

\section{Citation for published version (APA):}

Li, Z., Pan, F., Li, R., Pambou, E., Hu, X., Ruane, S., Ciumac, D., Li, P., Welbourn, R. J. L., Webster, J. R. P., Bishop, S. M., Narwal, R., Walle, C. F. V. D., \& Lu, J. R. (2018). Coadsorption of a Monoclonal Antibody and Nonionic Surfactant at the SiO2/Water Interface. A C S Applied Materials and Interfaces, 10(51), 44257-44266. https://doi.org/10.1021/acsami.8b16832

Published in:

A C S Applied Materials and Interfaces

\section{Citing this paper}

Please note that where the full-text provided on Manchester Research Explorer is the Author Accepted Manuscript or Proof version this may differ from the final Published version. If citing, it is advised that you check and use the publisher's definitive version.

\section{General rights}

Copyright and moral rights for the publications made accessible in the Research Explorer are retained by the authors and/or other copyright owners and it is a condition of accessing publications that users recognise and abide by the legal requirements associated with these rights.

\section{Takedown policy}

If you believe that this document breaches copyright please refer to the University of Manchester's Takedown Procedures [http://man.ac.uk/04Y6Bo] or contact uml.scholarlycommunications@manchester.ac.uk providing relevant details, so we can investigate your claim.

\section{OPEN ACCESS}


ACS Appl. Mater. Interfaces, 2018, 10 (51), pp 44257-44266

DOI: 10.1021 /acsami.8b16832

Publication Date (Web): November 30, 2018

\title{
Co-adsorption of a Monoclonal Antibody and Nonionic Surfactant at the $\mathrm{SiO}_{2} /$ water Interface
}

\author{
Zongyi $\mathrm{Li}^{1}$, Fang $\mathrm{Pan}^{1}$, Ruiheng $\mathrm{Li}^{1}$, Elias Pambou ${ }^{1}$, Xuzhi Hu${ }^{1}$, Sean Ruane ${ }^{1}$, Daniela \\ Ciumac $^{1}$, Peixun Li ${ }^{2}$, Rebecca J L Welbourn ${ }^{2}$, John R P Webster ${ }^{2}$, Steven M. Bishop ${ }^{4}$, \\ Rojaramani Narwal ${ }^{4}$, Christopher F van der Walle ${ }^{3}$, Jian Ren $\mathrm{Lu}^{1}$
}

${ }^{1}$ Biological Physics Laboratory, School of Physics and Astronomy, University of Manchester, Oxford Road, Schuster Building, Manchester M13 9PL, UK.

${ }^{2}$ ISIS Neutron Facility, STFC, Chilton, Didcot OX11 0QZ, UK.

${ }^{3}$ Formulation Sciences, MedImmune Ltd, Sir Aaron Klug Building, Granta Park, Cambridge CB21 6GH, UK

${ }^{4}$ Formulation Sciences, MedImmune LLC, Gaithersburg, MD 20878, USA.

Corresponding author: Jian R Lu

(email: j.lu@manchester.ac.uk; Tel: +44 161 2003926)

ZL and FP made equal contributions

\section{Keywords:}

Immunoglobulin, polysorbate 80, interfacial adsorption, structural unfolding, self-assembly, bilayer, neutron reflection, spectroscopic ellipsometry 


\begin{abstract}
During the formulation of therapeutic monoclonal antibodies (mAbs), nonionic surfactants are commonly added to attenuate structural rearrangement caused by adsorption/desorption at interfaces during processing, shipping and storage. We examined the adsorption of a mAb (COE-3) at the $\mathrm{SiO}_{2} /$ water interface in the presence of pentaethylene glycol monododecyl ether $\left(\mathrm{C}_{12} \mathrm{E}_{5}\right)$, polysorbate 80 (PS80-20EO) and a polysorbate 80 analogue with 7 ethoxylates (PS80-7EO). Spectroscopic ellipsometry (SE) was used to follow COE-3 dynamic adsorption and neutron reflection (NR) was used to determine interfacial structure and composition. Neither PS80-20EO nor $\mathrm{C}_{12} \mathrm{E}_{5}$ had a notable affinity for COE-3 or the interface under the conditions studied, and thus did not prevent COE-3 adsorption. In contrast, PS80-7EO did coadsorb but did not influence the dynamic process or the equilibrated amount of absorbed COE-3. Near equilibration, COE-3 underwent structural rearrangement and PS80-7EO started to bind the COE-3 interfacial layer and subsequently formed a well-defined surfactant bilayer via self-assembly. The resultant interfacial layer was comprised of an inner mAb layer of some $70 \AA$ thick and an outer surfactant layer of a further $70 \AA$, with distinct transitional regions across the mAb-surfactant and surfactant-bulk water boundaries. Once formed, such interfacial layers were very robust and worked to prevent further $\mathrm{mAb}$ adsorption, desorption and structural rearrangement. Such robust interfacial layers could be anticipated to exist for formulated mAbs stored in type II glass vials; further research is required to understand the behaviour of these layers for siliconized glass syringes.
\end{abstract}




\section{Introduction}

Monoclonal antibodies (mAbs) provide important treatments in several therapeutic areas, with recent excitement focussed on immune checkpoint inhibitors (immuno-oncology). ${ }^{1}$ However, irrespective of the therapeutic area, technical hurdles must be overcome in product processing, packaging and storage so that the product generated is robust in terms of stability and has an acceptable shelf-life. An attractive route that has been explored and further developed over the recent years is to formulate mAbs in concentrated aqueous solution ready for clinical administration by the subcutaneous route. ${ }^{2-4}$ MAb molecules can undergo adsorption and desorption, and this molecular process can elicit structural rearrangement, possibly leading to $\mathrm{mAb}$ aggregation, particulates and/or phase separation. ${ }^{5-11}$ This cascade of interfacial molecular events may cause loss of bioactivity, anti-drug antibody response and, potentially, immunogenicity. ${ }^{12,13}$

Addition of nonionic surfactants into mAb formulations is widely thought to inhibit protein adsorption. Many studies including our work have already shown that nonionic surfactants can prevent protein adsorption at the air/water interface when their concentrations are sufficiently high, ${ }^{14,15}$ but it is also important to understand how they can influence mAb adsorption at the solid/water interface. This study aims to investigate how a mAb and a nonionic surfactant may co-adsorb, and if it is possible to prevent mAb adsorption at the solid/water interface.

In the much broader context, adsorption of proteins has both fundamental and practical significance. ${ }^{16}$ Whilst there are many cases where protein adsorption is undesired, there are also other cases where the opposite is true. An example of the former is the fouling of proteins to porous membranes used in protein filtration which can cause membrane blockage and halt the process. In contrast, immobilization of extracellular membrane proteins onto implants can improve their integration with local tissue, thereby enhancing their chances of successful deployment and function.

Although the co-adsorption of a protein and surfactant can be similarly studied, ${ }^{5-11,14,15}$ the difficulty often lies in the ability to distinguish adsorbed protein from surfactant and water at the interface. Techniques such as fluorescence measurement, dual polarisation interferometry and spectroscopic ellipsometry (SE) can provide useful indications relating to the amount of materials adsorbed. In contrast, neutron reflection (NR) together with deuterium labelling 
can reveal the thickness and composition of adsorbed protein with and without surfactant. $^{5,14,16-20}$ NR data together with the known globular structures of proteins allow us to determine how interfacial adsorption and surfactant binding affect the conformational orientation of the adsorbed protein molecules, from which the extent of structural rearrangement can be inferred.

A protein molecule is folded from one or more polypeptide chain(s), often forming a welldefined 3-dimensional structure. Interfacial adsorption can cause structural deformation or unfolding, resulting in the loss of its bioactivity. Due to their relative structural simplicity, lysozyme, human serum albumin (HSA) and bovine serum albumin (BSA) have been used to examine the general features of protein adsorption with and without surfactants. ${ }^{18,21,22}$ Ionic surfactants such as sodium dodecyl sulphate (SDS) and dodecyl trimethyl ammonium bromide $\left(\mathrm{C}_{12} \mathrm{TAB}\right)$ can bind to pre-adsorbed proteins, causing unfolding. They are thus unsuitable for therapeutic mAb stabilization.

In contrast, nonionic surfactants are considered to have a negligible effect on protein structure, although there has been limited investigation of how they can prevent protein adsorption at the solid/water interface. $\mathrm{A}$ mAb is comprised of 1 fragment crystallization $(\mathrm{Fc})$ and 2 fragment antigen-binding arms (Fabs). The Fc is formed from the two constant domains $\left(\mathrm{C}_{\mathrm{H}} \gamma 3\right.$ and $\left.\mathrm{C}_{\mathrm{H}} \gamma 2\right)$ of each heavy chain, and each Fab is formed from the $\mathrm{C}_{\mathrm{H} \gamma 1}$ and variable domain $\left(V_{H}\right)$ together with the light chain $C_{L} \kappa / \lambda$ and $V_{L}$ domains. Because of their relatively large molecular size, ${ }^{23,24}$ a mAb molecule would have a greater area of contact with the substrate upon interfacial adsorption. Nonionic surfactants would therefore have to be sufficiently surface active to provide the desired effect of preventing mAb adsorption.

In this work, we chose pentaethylene glycol monododecyl ether $\left(\mathrm{C}_{12} \mathrm{E}_{5}\right)$, polysorbate 80 (PS80-20EO) and a polysorbate 80 analogue with 7 ethoxylates (PS80-7EO) to examine how they could co-adsorb when mixed with mAb COE-3, and if they could prevent COE-3 adsorption. Because of their different sizes and hydrophobicities, these surfactants could interact with COE-3 differently, thereby offering the potential to mediate COE-3 adsorption or co-adsorption. COE-3 is an immunoglobulin-1 (IgG1) with sequence modifications in the variable and constant domains of the Fab, as necessitated during its design in the biopharmaceutical industry. ${ }^{14,17}$ Its solution properties and surface and interfacial adsorption have been extensively studied. ${ }^{14,17,25}$ This study of its co-adsorption with representative 
nonionic surfactants at the solid/water interface represents an important step towards unravelling the associated molecular interactions.

By combining the capabilities of following the dynamic process by SE with structural determination from NR, this work aims to unravel how COE-3 molecules adsorb in the presence of different nonionic surfactants. Since COE-3 represents the IgG1 isotype which is common to many therapeutic mAbs, the nature of its adsorption studied here and elsewhere ${ }^{14,17,26}$ is relevant to the wider bioprocess industry. The $\mathrm{SiO}_{2}$ surface is a good mimic of a glass surface and thus the co-adsorption studies here model mAb adsorption to (non-siliconized) glass vial and syringe container closures.

\section{Materials and Experimental Methods}

\subsection{Materials}

COE-3 is a human IgG1 $\kappa$ isotype with a molecular weight (MW) of 144,750 and isoelectric point (pI) of $8.44 .^{25}$ The mAb was expressed in Chinese hamster ovary cells and purified using industry-standard methods. It was supplied as a stock solution of $46.4 \mathrm{mg} / \mathrm{ml}$ in 'His buffer' (25 mM histidine/histidine hydrochloride, $7 \%$ w/v sucrose, $\mathrm{pH}$ 6.0, batch no. SP12423) and stored at $-80{ }^{\circ} \mathrm{C}$. When a solution preparation was needed, the stock was thawed and diluted directly into His buffer prepared with $\mathrm{H}_{2} \mathrm{O}$ for a range of $\mathrm{pH}$ values and mAb concentrations as required for SE measurements, or with $\mathrm{D}_{2} \mathrm{O}$ and contrast matched to antibody (CM2.58) buffers at the equivalent $\mathrm{pH}$ for NR measurements. Despite the original stock solution being in $\mathrm{H}_{2} \mathrm{O}$, the large dilutions made into CM2.58 and $\mathrm{D}_{2} \mathrm{O}$ resulted in only very low changes in the scattering length density (SLD) of the solvents, but the exact amounts were taken into account during neutron data analysis. As the sequences of the light and heavy chains of COE-3 are known, ${ }^{14,17}$ its scattering length (SL) and scattering length density (SLD, $\rho$ ) in CM2.58 and $\mathrm{D}_{2} \mathrm{O}$ are listed in Table $\mathrm{S} 1$.

Surfactants Pentaethylene glycol monododecyl ether $\left(\mathrm{C}_{12} \mathrm{E}_{5}\right.$, from Sigma, $99 \%$ pure $)$ was used as received; all nonionic surfactants were aliquoted into small batches and stored at $4{ }^{\circ} \mathrm{C}$. The molecular structure of the hydrogenated PS80 is schematically shown in Figure S1. It has 20 ethoxylates (denoted as PS80-20EO) and is widely studied for its capacity to stabilize protein biotherapeutics. Following the recent work by Tucker et al., on the examination of 
the impact of the acyl chain length and head group size of this group of surfactants on their interaction with hydrophobin, ${ }^{27}$ we synthesised PS80 with 7 ethoxylates, with the head group hydrogenated (HPS80-7EO) and deuterated (DPS80-7EO). The respective SLs and SLDs for these surfactants are also shown in Table S1. Griffin ${ }^{28}$ has developed a method for estimating the amphiphilicity of nonionic surfactants via the so-called hydrophilic-lipophilic balance (HLB) as follows:

$$
H L B=20 \frac{M h}{M W}
$$

where $M h$ is the molecular mass of the hydrophilic head of the molecule, and $M W$ is the mass of the entire nonionic surfactant molecule, giving a result between 0 and 20 with 0 corresponding to a completely hydrophobic molecule and 20 corresponding to a completely hydrophilic one. From equation (1) the HLB values were estimated to be 11.7 for $\mathrm{C}_{12} \mathrm{E}_{5}, 9.9$ for PS80-7EO and 14.3 for PS80-20EO.

Silicon wafers and blocks Silicon wafers ( $<111>$ orientations, minimal doping) with $10 \mathrm{~cm}$ diameter and one side optically flat were purchased from Compart Technology, UK. They were cut into $2 \times 2 \mathrm{~cm}^{2}$ to fit the solid/liquid cell specially built for SE measurements. The large faces of silicon blocks $\left(5 \times 8 \times 1.2 \mathrm{~cm}^{3}\right)$, also $<111>$ orientations) were polished into optically flat by Crystran Ltd (Poole, UK). The optically flat silicon surfaces bear an ultrathin native oxide layer. Before use, all the wafer and block surfaces were carefully rinsed with dilute Decon (neutral, containing 3-5\% of the concentrated stock supplied by Decon UK) and then a large excess of pure water before drying, to ensure they were thoroughly clean.

Buffers. Pure $\mathrm{H}_{2} \mathrm{O}$ was processed from an Elgastat PURELAB purification system. $\mathrm{D}_{2} \mathrm{O}(99 \%$ D), histidine and histidine hydrochloride were purchased from Sigma-Aldrich and used as supplied.

\subsection{Spectroscopic Ellipsometry (SE)}

SE measures the variation of the light polarisation state from the reflection at the sample surface or interface. Two optical parameters $\Delta$ and $\Psi$ are used to describe this variation, with $\Delta$ showing the wave phase changes in $p$ and $s$ polarisations, and $\Psi$ showing the wave 
amplitude differences. The sample ellipticity, $\rho$, is expressed as the ratio of the Fresnel reflection coefficients of $p$ and $s$ polarizations,$r_{p}$ and $r_{s}$, respectively: ${ }^{18,29}$

$$
\rho=\tan \psi \cdot e^{i \Delta}=\frac{r_{p}}{r_{s}}
$$

The experimental data were analyzed using the software developed by J.A. Woollam Co. Inc. Data analysis starts with the assumed interfacial structure model incorporating the sample layer from which $\rho, \Delta$ and $\Psi$ can be calculated theoretically from equation (2). The fitting to the experimental data via a regression process leads to the thickness and refractive index when the MSE (mean squared errors) between measured and simulated data is minimal.

The dispersion relationship of sample refractive index is described by the Cauchy equation for a transparent and homogeneous material:

$$
n(\lambda)=A+\frac{B}{\lambda^{2}}
$$

where $\lambda$ is the wavelength; $A$ and $B$ are the Cauchy coefficients which were taken as 1.45 and 0.003 , respectively, in this work. The surface excess $\Gamma\left(\mathrm{mg} / \mathrm{m}^{2}\right)$ of the sample was calculated from the refractive index $n$ and sample thickness $\tau$ by De Feijter's formula: ${ }^{30}$

$$
\Gamma=\frac{\tau\left(n-n_{0}\right)}{(d n / d c)}
$$

where $n$ and $n_{0}$ are the refractive indices of the sample and the ambient environment; $d n / d c$ is the refractive index increment of the sample which was assumed to be $0.18 \mathrm{ml} / \mathrm{g}$ for protein and $0.12 \mathrm{ml} / \mathrm{g}$ for surfactants in this work.

A common technical challenge with the study of ultrathin films ( $<50-100 \AA$ ) by SE lies in the difficulty in decoupling layer thickness from the refractive index, but the product always ensures good consistency and reliability. In checking the thicknesses of the native oxide layers on silicon wafer cuts and polished neutron blocks, it was assumed that the refractive indices of the oxide layers were the same as that of the pure $\mathrm{SiO}_{2}$, with no pores or defects. The SE measurements led to consistent oxide layer thicknesses $13 \pm 2 \AA$. SE measurements at the solid/water interface were performed using a specially designed liquid cell with a pair of quartz windows to allow light entering and exiting from the reflecting interface. The windows were aligned to be perpendicular to the incoming and exiting light beams. A silicon wafer cut $(2 \times 2 \mathrm{~cm})$ was confined at the centre of the liquid cell bottom and thus enabled the 
light beam entering and becoming reflected at $70^{\circ}$ to the surface normal. A useful check of the window alignment was the consistent thickness of the native oxide layer at the solid/water interface. The amount lysozyme adsorbed at $1 \mathrm{mg} / \mathrm{ml}$ and $\mathrm{pH} 7$ could help check the consistent hydrophilicity of the wafer surfaces after cleaning. ${ }^{31}$

\subsection{Neutron Reflection (NR)}

Neutron reflection measurements were undertaken on the SURF and INTER reflectometers at ISIS Neutron Facility, Rutherford Appleton Laboratory, UK. The polished and freshly cleaned face of the silicon block was clamped against a purposely-built liquid cell. The setup was then mounted on the sample stage, and alignment was made to ensure the neutron beam to be specularly reflected from the solid/liquid interface and collected by the detector. The illuminated area at the solid/liquid interface was defined by a series of collimation slits to give a footprint of $60 \mathrm{~mm}$ and a resolution of $5 \%$ in Q. A transmission through the solid block was used to normalise the data.

The data measured on INTER was collected in event mode to help study the dynamics of the adsorption process, which allows the data to be processed into histograms of varying duration. $^{32}$ In this paper, the raw data was split into 2 minute intervals to ensure sufficient statistics in each data slice. The software called MantidPlot ${ }^{33}$ was used to perform the initial data reduction. The reduced data were further analyzed using the software named Motofit, ${ }^{34}$ which could calculate the reflectivity profile from a simulation model based on neutron reflection theory and the Abeles optical matrix method as described in our previous work. ${ }^{35,36}$ The simulation model contained a series of thin layers with adjustable parameters such as layer thickness $\tau_{i}$ and average scattering length density $\left(S L D_{i}\right.$ or $\left.B_{i}\right)$. The difference between a measured profile and the simulated one is quantified by $\chi^{2}$ in the least-squares method. The optimal fit was found when $\chi^{2}$ tended to the minimum. The $B_{i}$ of each layer $i$ can be expressed as:

$$
B_{i}=\phi_{a} b_{a}+\phi_{h} b_{h}+\phi_{t} b_{t}+\phi_{w} b_{w}
$$

where $\phi$ stands for the volume fraction of the antibody $(a)$, surfactant head group $(h)$, surfactant tail group $(t)$ and water as solvent $(w) ; b$ is the scattering length density of each component. The sum of volume fractions should always be unity. 
For the adsorbed layer containing antibody only, the values of $\phi_{t}$ and $\phi_{h}$ are zero. Therefore, the volume fraction of antibody $\phi_{a}$ was calculated straightforwardly with known values of $b_{a}$ and $b_{w}$ as listed in Table S1. For the layer involving 2 or more sample materials, volume fractions can be determined by solving equation (5) from a set of parallel experiments measured under different isotopic contrasts but analysed using the same structural model. The results were given in Table S2. The structure parameters from the structural model did slightly vary between parallel experiments, but based on the sensitivity and tolerance fitted their average values and deviations were also presented in Table S2.

The adsorbed mass $\Gamma_{i}$ of each component can be estimated from

$$
\Gamma_{i}=\frac{\tau \cdot \phi_{i} \cdot M_{w}}{V \cdot N_{A}}
$$

where $V$ and $M_{w}$ are molecular volume and molecular weight; $N_{A}$ is the Avogadro constant; $\phi_{i}$ denotes the volume fraction of the component in the layer; $\tau$ is the layer thickness.

NR dynamic measurements of co-adsorption and sequential adsorption were taken under only one isotopic contrast in this work, i.e., using hydrogenated surfactant in $\mathrm{D}_{2} \mathrm{O}$. Although we cannot work out the volume fraction of each adsorbed component using equation (5) with only one isotopic contrast, useful information can be obtained from the data fitting to show dynamic changes.

\section{Results and Discussion}

\subsection{Adsorption of COE-3 at the $\mathrm{Bare}^{\mathrm{SiO}} \mathrm{O}_{2}$ water Interface}

SE measurements were first made to determine the thickness of the native oxide layer on the surface of each silicon wafer to ensure the surface to be clean. The oxide layer was fitted to $13 \pm 2 \AA$ for all wafer cuts used, suggesting good consistency; it was assumed that the layers were free from defects with a refractive index equal to amorphous $\mathrm{SiO}_{2}$. Similar $\mathrm{SE}$ measurements at the air/solid interface were also undertaken for the large polished faces of the silicon blocks before neutron reflection. On each surface, SE measurements were undertaken at the middle and 2 side points $1 \mathrm{~cm}$ away from the edge. The thicknesses were very consistent with the values obtained from the wafer cuts, suggesting similar surface oxide 
structures between them. Subsequent measurements were made at the solid/water interface using a purposely-built SE liquid cell for the wafer cuts. Similar oxide thicknesses were obtained and this process ensured good window alignment before proceeding to the study of COE-3 adsorption. Figure 1 shows $\Psi$ (Figure 1(a)) and $\Delta$ (Figure 1(b)) measured from the $\mathrm{SiO}_{2} /$ water interface at 1,5 and $30 \mathrm{~min}$, with the concentration of COE-3 fixed at $0.01 \mathrm{mg} / \mathrm{ml}$ in the aqueous His buffer, $\mathrm{pH} 5.5$, ionic strength $25 \mathrm{mM}$. The continuous lines represent the best model fits to the respective measured data, with the oxide layer thickness fixed at $13 \pm 1$ $\AA$ A. As evident from Figure 1, changes in $\Psi$ arising from the time-dependent COE-3 adsorption are small, but for $\Delta$ the changes are significant.

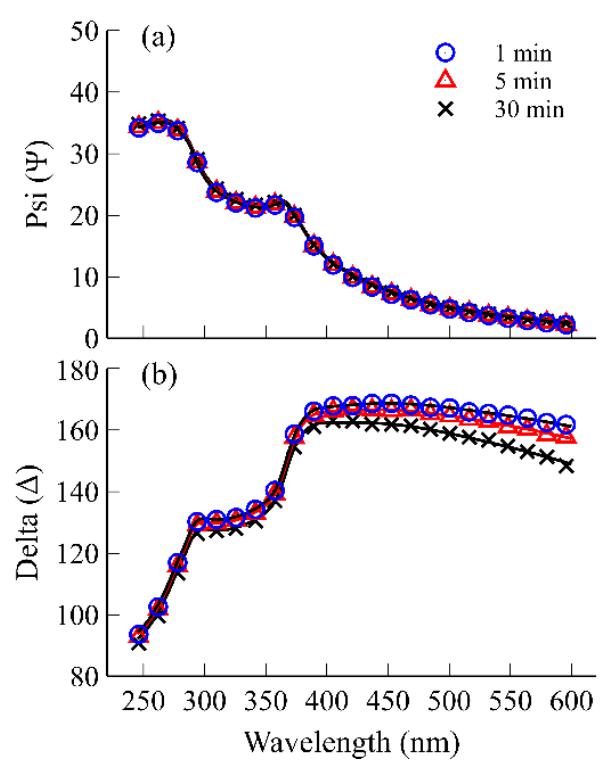

Figure 1. Ellipsometric scans of the amplitude component $\Psi$ (a) and the phase difference $\Delta$ (b) against wavelength measured at the $\mathrm{SiO}_{2} /$ water interface for $0.01 \mathrm{mg} / \mathrm{ml} \mathrm{COE}-3$ in $25 \mathrm{mM}$ His buffer, $\mathrm{pH}$ 5.5; after 1,5 and $30 \mathrm{~min}$ of adsorption. The continuous lines show the uniform layer fits of the $\mathrm{SiO} 2$ layer of $13 \pm 1 \AA$.

Similar to the data shown in Figure 1, plots of changes in $\Psi$ and $\Delta$ were also obtained against time at other COE-3 concentrations. Fitting to each pair of $\Psi$ and $\Delta$ led to the layer's refractive index and thickness from which the adsorbed amount of COE-3, $\Gamma$, could be calculated from the De Feijter's formula, equation (4). In the analysis of these $\Psi$ and $\Delta$ pairs, the refractive index and thickness of the $\mathrm{SiO}_{2}$ layer were fixed. To avoid any irrational variations arising from the coupling of the refractive index and thickness of the mAb layer in the fitting, A was fixed at 1.45 in equation (3). This means the matching thickness was nominal and would not have any bearing on the change of the real mAb layer thickness. However, the treatment of fixing A was for simplicity and did not affect the determination of 
$\Gamma$. Figure S2 shows the time-dependent changes of $\Gamma$ at COE-3 concentrations of 10, 50, 100 and $200 \mathrm{ppm}$; at $10 \mathrm{ppm}$ equilibration was reached in $\sim 15 \mathrm{~min}$. In contrast, for COE-3 concentrations $\geq 50 \mathrm{ppm}$, the initial dynamic process reached equilibration after $\sim 2 \mathrm{~min}$ (Figure S2). As COE-3 concentration increased, $\Gamma$ was almost constant at $2.4 \mathrm{mg} / \mathrm{m}^{2}$ (Figure $2)$, consistent with the data from our previous studies. ${ }^{26}$

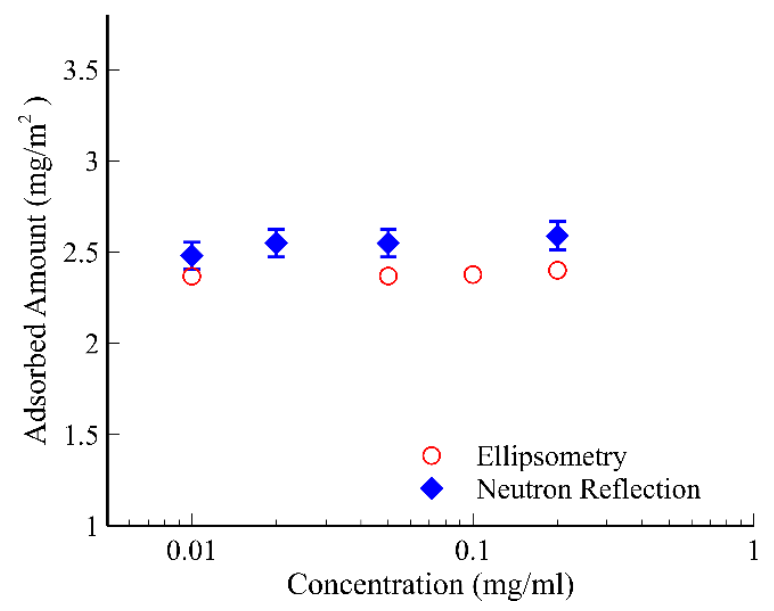

Figure 2. Surface saturated adsorbed amount of COE-3 at the $\mathrm{SiO}_{2} /$ water interface measured by $\mathrm{SE}$ and $\mathrm{NR}\left(\mathrm{D}_{2} \mathrm{O}\right.$ under the same His buffer conditions) plotted against concentration.

NR measurements were made at the $\mathrm{SiO}_{2}$ /water interface under the same conditions as for $\mathrm{SE}$ experiments, except that $\mathrm{D}_{2} \mathrm{O}$ buffer was used to improve the isotopic contrast and signal. Figure 3 shows reflectivity profiles measured under a set of COE-3 concentrations with that measured from the $\mathrm{SiO}_{2} / \mathrm{D}_{2} \mathrm{O}$ interface as control. For clarity, the reflectivity profiles were displaced by plotting with a $0.2^{\mathrm{n}}$ offset from the highest concentration. The difference in shape between that measured at $10 \mathrm{ppm}$ and the control (buffer) clearly indicates COE-3 adsorption.

Unlike SE fitting, modelling the reflectivity measured at the $\mathrm{SiO}_{2} / \mathrm{D}_{2} \mathrm{O}$ interface yielded the independent determination of layer thickness and scattering length density (SLD or $B$ ), equivalent to $n$ in SE. The oxide layer was also found to be $13 \pm 1 \AA$. Subsequent analysis of the structure of the adsorbed COE-3 layer was undertaken by fixing the oxide layer structure and assuming that COE-3 was adsorbed onto the oxide surface. It was found that the measured reflectivity profiles could be represented by assuming the formation of a single adsorbed COE-3 layer about 52-55 А. However, further improvement was achieved by assuming a dense inner layer together with a diffuse outer layer into the aqueous phase. The consistency between the fitted (continuous lines) and measured data as shown in Figure 3 
adds confidence in the quality of the model analysis adopted, showing a good representation of the distribution of the adsorbed COE-3 layers in the 2-layer model. The key structural parameters obtained from the 2-layer model fits are listed in Table 1.

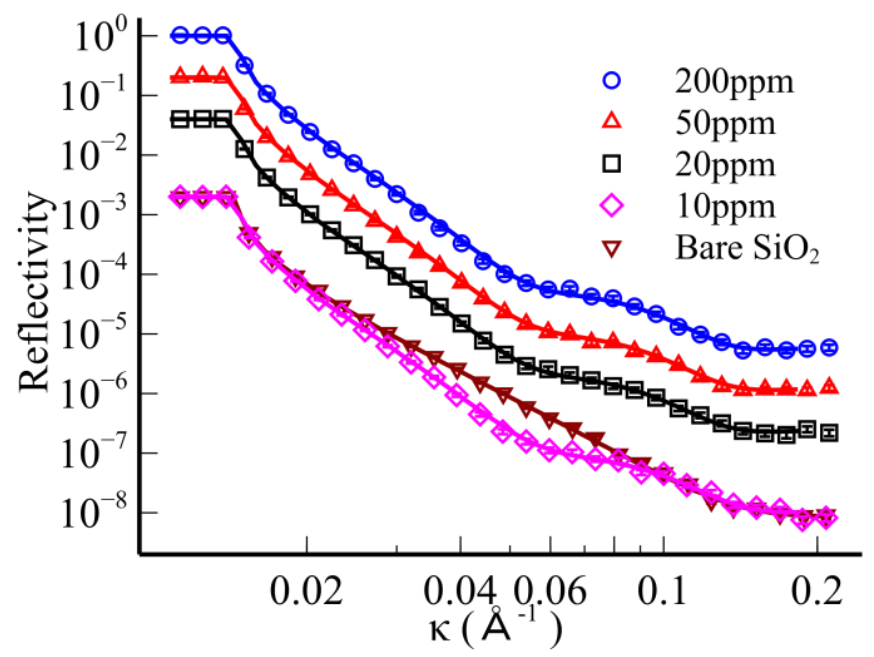

Figure 3. NR profiles measured at the $\mathrm{SiO}_{2} / \mathrm{D}_{2} \mathrm{O}$ interface for COE-3 adsorption at $0,0.01,0.02,0.05$ and $0.2 \mathrm{mg} / \mathrm{ml}$ bulk concentration in $25 \mathrm{mM}$ His buffer, $\mathrm{pH} 5.5$; the continuous lines denote the best fits for each profile with the fitted parameters showed in Table 1. For clarity, the profiles were plotted with a $0.2^{\mathrm{n}}$ offset.

\begin{tabular}{|c|c|c|c|c|c|c|c|c|c|}
\hline $\begin{array}{l}\text { Conc. } \\
\text { mgml }^{-1}\end{array}$ & Layer & $\begin{array}{c}S L D \\
\pm 0.1 / 10 \\
{ }^{6} \AA^{-2}\end{array}$ & $\begin{array}{c}\text { Thickness } \\
\pm 1 / \AA\end{array}$ & $\begin{array}{l}\phi_{C O E-3} \\
\pm 0.01\end{array}$ & $\begin{array}{l}\phi_{\text {water }} \\
\pm 0.01\end{array}$ & $\begin{array}{c}\text { Mol Density } \\
10^{-8} \mathrm{Molm}^{-2}\end{array}$ & $\begin{array}{l}\Gamma_{\boldsymbol{C O E - 3}} \\
{m g m^{-2}}^{-2}\end{array}$ & $\begin{array}{c}\text { Total } \\
\text { Thickness } \\
\AA\end{array}$ & $\begin{array}{c}\text { Total } \Gamma_{\text {COE-3 }} \\
\text { mgm }^{-2}\end{array}$ \\
\hline \multirow{2}{*}{0.01} & Inner & 5.2 & 45 & 0.35 & 0.65 & 1.53 & $2.26 \pm 0.05$ & \multirow{2}{*}{$65 \pm 2$} & \multirow{2}{*}{$2.48 \pm 0.06$} \\
\hline & Outer & 6.0 & 20 & 0.08 & 0.92 & 0.15 & $0.22 \pm 0.01$ & & \\
\hline \multirow{2}{*}{0.02} & Inner & 5.2 & 45 & 0.36 & 0.64 & 1.56 & $2.30 \pm 0.05$ & \multirow{2}{*}{$65 \pm 2$} & \multirow{2}{*}{$2.55 \pm 0.06$} \\
\hline & Outer & 6.0 & 20 & 0.09 & 0.91 & 0.17 & $0.25 \pm 0.01$ & & \\
\hline \multirow{2}{*}{0.05} & Inner & 5.2 & 45 & 0.36 & 0.64 & 1.56 & $2.30 \pm 0.05$ & \multirow{2}{*}{$65 \pm 2$} & \multirow{2}{*}{$2.55 \pm 0.06$} \\
\hline & Outer & 6.0 & 20 & 0.09 & 0.91 & 0.17 & $0.25 \pm 0.01$ & & \\
\hline \multirow{2}{*}{0.2} & Inner & 5.2 & 45 & 0.37 & 0.63 & 1.59 & $2.35 \pm 0.05$ & \multirow{2}{*}{$65 \pm 2$} & \multirow{2}{*}{$2.59 \pm 0.06$} \\
\hline & Outer & 6.0 & 20 & 0.09 & 0.91 & 0.17 & $0.25 \pm 0.01$ & & \\
\hline
\end{tabular}

Table 1. The best fitted parameters to the neutron reflection profiles as shown in Figure 3 by modelling the COE-3 adsorbed layer using a 2-layer model, with the adsorbed amount $(\Gamma)$ calculated from equation (6). Error values were estimated from experimental uncertainties.

It can be seen from Table 1 that the main features obtained from the 2-layer model analysis are similar in that the main layer is $45 \AA$ and the diffuse outer layer is $20 \AA$. The only difference is the small but measurable change in the SLD of the main layer. As explained previously, the NR measurements were undertaken 1-2 $\mathrm{hr}$ after the solutions were in contact with the $\mathrm{SiO}_{2}$ surface and the data were thus representative of the equilibrated adsorption. 
The adsorbed amount was also plotted in Figure 2 where it can be seen that the SE and NR data are highly consistent within experimental errors.

\subsection{Adsorption of Nonionic Surfactants at the $\mathrm{SiO}_{2} /$ Water Interface}

Adsorption of nonionic surfactants at the $\mathrm{SiO}_{2}$ /water interface has been previously studied by several groups using various methods including $\mathrm{SE}$ and $\mathrm{NR}^{37,38}$. Nonionic surfactants such as $\mathrm{C}_{12} \mathrm{E}_{5}$ and $\mathrm{C}_{12} \mathrm{E}_{6}$ can adsorb at the interface but the exact amount is highly dependent on solution $\mathrm{pH}$, ionic strength and surface treatment. Under the buffer conditions used in this work (25 mM His buffer, $\mathrm{pH} 5.5$ ), $\mathrm{C}_{12} \mathrm{E}_{5}$ showed very weak adsorption (Figure S3), possibly caused by the relatively high ionic strength compared to other work reported previously. There was no sign of adsorption from PS80 with 7 or 20 ethoxylates (Figure S3) over a wide concentration range: note that the concentration of $0.2 \mathrm{mg} / \mathrm{ml}$ is more than 10 times the CMC of PS80 (Tween ${ }^{\circledR}$ 80). Reducing the ionic strength could lead to nonionic surfactant adsorption, but the amount adsorbed from PS80-20EO was low due to its high hydrophilicity. In the buffers considered for therapeutic mAb stabilisation, the ionic strength is usually even higher than what has been used in this work (equivalent to $200 \mathrm{mM}$ ).

\subsection{Co-adsorption of COE-3 and PS80-20EO and $\mathrm{C}_{12} \mathrm{E}_{5}$}

Co-adsorption of COE-3 and PS80-20EO at the bare $\mathrm{SiO}_{2} /$ water interface was first undertaken using a solution containing $0.01 \mathrm{mg} / \mathrm{ml}(10 \mathrm{ppm})$ COE-3 and $0.2 \mathrm{mg} / \mathrm{ml}$ PS8020EO, in His buffer, $\mathrm{pH} 5.5$, ionic strength $25 \mathrm{mM}$. Figure 4(a) shows that the timedependent adsorption measured by SE was comprised of two distinct stages: a rapid adsorption within 12-13 min followed by a decline towards the plateau, with $\Gamma$ of $\sim 2.5 \mathrm{mg} / \mathrm{m}^{2}$ at equilibrium.

The adsorption of COE-3 alone at the same concentration and solution conditions is also shown for comparison in Figure 4(a). The adsorption profile is the same as that measured from the mixture, demonstrating that PS80-20EO did not co-adsorb. When the equilibrated solution of $0.01 \mathrm{mg} / \mathrm{ml} \mathrm{COE-3}$ was replaced by $0.2 \mathrm{mg} / \mathrm{ml}$ PS80-20EO, no change in $\Gamma$ was observed, indicating that the surfactant neither co-adsorbed nor washed-off pre-adsorbed COE-3. 
At a COE-3 concentration of $0.1 \mathrm{mg} / \mathrm{ml}(100 \mathrm{ppm})$, the adsorption profile again tended to saturation with an adsorbed amount of $\sim 2.5 \mathrm{mg} / \mathrm{m}^{2}$ but after a much more rapid initial dynamic adsorption process within 4 min (Figure 4(b); the slight decrease in the adsorption curve after plateau likely represents an instability in the measuring-cell setup. Replacement of the mAb solution by that of $0.2 \mathrm{mg} / \mathrm{ml}$ PS80-20EO did not alter this adsorption profile, again indicating the absence of surfactant influence on the pre-adsorbed COE-3 layer. Furthermore, the dynamic adsorption profile for the COE-3 and PS80-20EO mixture at the same concentrations and buffer overlaps with that of COE-3 alone, supporting the previous data implying no measurable surfactant co-adsorption.

In this work, $\mathrm{C}_{12} \mathrm{E}_{5}$ was used to complement PS80, but to assess COE-3 adsorption behaviour at neutral $\mathrm{pH}$, closer to its isoelectric point ( 8.4). As evident from Figure 4(c), the main features of the COE-3 adsorption profile remain the same but the dynamic process leading to the plateau is slower, and the equilibrium adsorbed amount is higher $\left(3.4 \pm 0.2 \mathrm{mg} / \mathrm{m}^{2}\right)$. Because the adsorption profile of the solution mixture of $\mathrm{COE}-3$ and $\mathrm{C}_{12} \mathrm{E}_{5}$ (also at a concentration $10 \times$ above its $\mathrm{CMC}$ ) again overlapped with COE-3 alone, it can be inferred that the co-adsorption of $\mathrm{C}_{12} \mathrm{E}_{5}$ is close to zero (as for PS80-20EO). The higher adsorbed amount at equilibrium can, therefore, be attributed to the higher $\mathrm{pH}$ rather than the change in the nature of the nonionic surfactant.
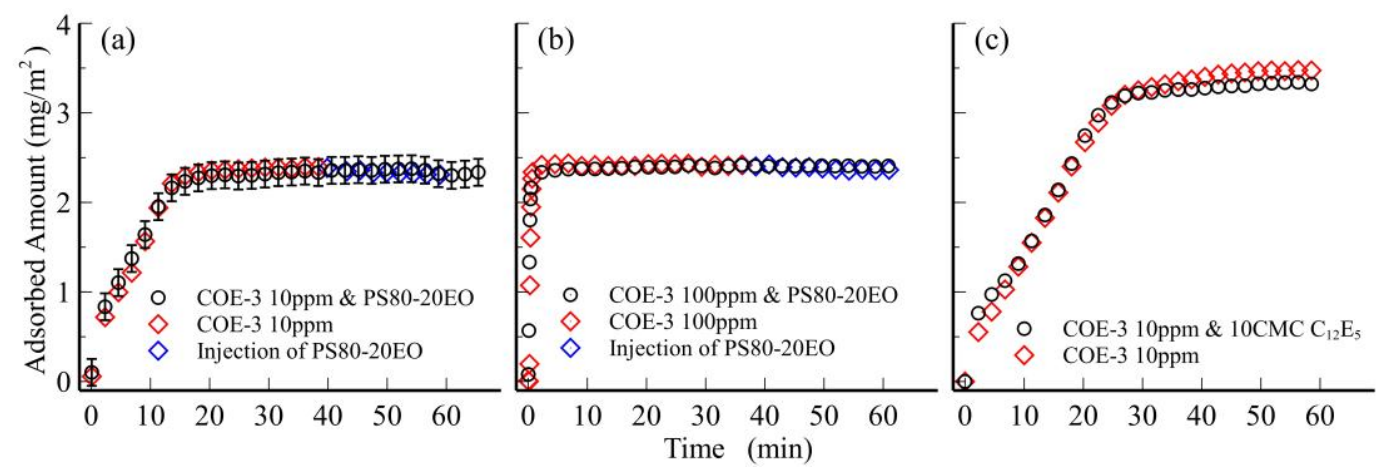

Figure 4. Interface adsorbed amount $(\Gamma)$ plotted against time measured by $\mathrm{SE}$ at the $\mathrm{SiO}_{2} /$ water interface for COE-3 adsorption with and without surfactants in $25 \mathrm{mM}$ His buffer: (a) a mixed solution of $0.01 \mathrm{mg} / \mathrm{ml} \mathrm{COE-3} \mathrm{and} 0.2 \mathrm{mg} / \mathrm{ml} \mathrm{PS80-20EO} \mathrm{at} \mathrm{pH} 5.5$; (b) a mixed solution of 0.1 $\mathrm{mg} / \mathrm{ml} \mathrm{COE}-3$ and $0.2 \mathrm{mg} / \mathrm{ml}$ PS80-20EO at $\mathrm{pH} 5.5$; (c) a mixed solution of $0.01 \mathrm{mg} / \mathrm{ml} \mathrm{COE}-3$ and $\mathrm{C}_{12} \mathrm{E}_{5}$ (conc. $10 \times \mathrm{CMC}$ ) at $\mathrm{pH}$ 7. The red diamonds present the adsorption process of COE- 3 alone followed by blue diamonds for the injection of surfactants, while the black circles present the data measured from mixtures of COE-3 and surfactants. 


\subsection{Co-adsorption of COE-3 in the Presence of PS80-7EO}

The absence of measurable co-adsorption of COE-3 and PS80-20EO or $\mathrm{C}_{12} \mathrm{E}_{5}$ by SE likely arises from the surfactants' hydrophilicity. To test this hypothesis, we examined the coadsorption of COE-3 (10 and $100 \mathrm{ppm})$ and PS80-7EO $(0.2 \mathrm{mg} / \mathrm{ml})$ in His buffer, $\mathrm{pH} 5.5$, ionic strength $25 \mathrm{mM}$. The black circles in Figure 5(a) shows that the adsorption profile measured by SE for the COE-3 and PS80-7EO mixture has a more complicated three-stage process: the initial stage is a rapid dynamic adsorption which is almost indistinguishable from COE-3 alone, the second stage is a distinct and much slower dynamic adsorption over $\sim 50$ min before reaching plateau (third stage), with a higher adsorbed amount at equilibrium of 8 $\mathrm{mg} / \mathrm{m}^{2}$. Despite the equilibrium adsorbed amount differing little for a 10-fold increase in COE-3 concentration, shown in Figure S4, when comparing the adsorption profiles to those for COE-3 with PS80-20EO/ $\mathrm{C}_{12} \mathrm{E}_{5}$ mixtures, these data strongly imply that PS80-7EO coadsorbs at the interface.

To investigate the molecular mechanism underlying this adsorption profile, the effect of PS80-7EO on COE-3 adsorption was tested by replacement of the COE-3 solution by that of the surfactant. Upon introduction of PS80-7EO, a sequential adsorption profile that is almost parallel to that measured for the co-adsorption from the COE-3/PS80-7EO solution mixture was observed (Figure 5(b) and Figure S4), with the same value for $\Gamma$ at equilibrium. This implies that PS80-7EO adsorption in both cases occurs as a distinct process subsequent to the formation of a stable mAb layer.

The adsorption process for the same sample injections at the surface was also monitored using NR dynamic measurements; the NR profiles generated from the dynamic measurements are plotted with offsets in Figure 5 (c) and (d). Selected times through the process are shown to highlight the different steps, with each curve showing a 2 minute slice starting at the labeled time. In Figure 5 (c), the mixture of COE-3 and surfactant was injected onto the bare $\mathrm{SiO}_{2}$ surface at time 0 ; while in Figure 5 (d), the time starting point is set when the surfactant solution was injected to the pre-adsorbed COE-3 layer. The continuous lines denote the best fit for each profile, and in each case the fitting model contains a minimum number of stacked layers required to produce an acceptable replication to the measured reflectivity, the key fitted structural parameters listed in Table S3. 
A distinct feature in Figure 5(d) is the occurrence of sharp interference fringes caused by surfactant adsorption. This is in contrast to the weak and broad interference as displayed from COE-3 adsorption alone. The dimension of the equivalent uniform layer of the adsorbed materials, $d$, is inversely proportional to the wave vector or momentum transfer of the fringes (minima), $\kappa$, where

$$
d=\frac{(2 n+1) \pi}{\kappa}
$$

with $n$ being the integer. ${ }^{39}$ From this simple relation, we can estimate the thickness of the adsorbed materials. The fringe position of the NR dynamic measurement at 2 min is already close to the position of the equilibrated state, indicating that the adsorbed complex layer started to adopt the thickness close to its final structure once the surfactant sample was applied. The difference in amplitude between NR dynamic profiles at the different time resulted from the changing scattering length due to the increasing volume fraction of PS807EO. The exact total thickness of the adsorbed materials can be obtained by data fitting as outlined in Supporting Information with key structural parameters listed in Table S3, and also presented in the histogram in Figure 5 (b).

At the start of surfactant binding, a 2-layer model was found to be adequate to account for the entire interfacial structure. Over the subsequent few minutes, the interfacial layers could be modeled using a 3-layer model, but as shown from Table S3, a 4-layer model had to be used to fit the NR dynamic data after $8 \mathrm{~min}$, despite the similarity in the total thickness in each model. This observation reveals that the structure away from the interface becomes more defined so that discrete layers are required for the different regions, whereas initially, the top part of adsorbed materials is more diffuse.

In contrast, Figure 5 (c) shows the NR dynamic measurements following injection of the premixed COE-3 and surfactant sample. The reflectivity profile measured after 3 min appears to be a broad curve with the thickness of the adsorbed layer at this time analysed to be $30 \AA$. A much thicker layer around $130 \AA$ was obtained at $11 \mathrm{~min}$. Subsequently, the total adsorbed layer thickness changed little until the equilibrated state reached. The dramatic change in thickness suggests a transformation of the adsorbed layer structure which occurred in the first 10 min. Data presented in Table S3 indicate structural rearrangement in the adsorbed layers over time: the eventual 4-layer model fitting needed to account for the well-defined sub-layer structure within the interfacial mAb-surfactant complex. These NR structural features agree 
with the observations from the SE measurements and together show a 3-stage process for the co-adsorption of COE-3 and PS80-7EO: i) initial adsorption dominated by COE-3; ii) coadsorption of PS80-7EO upon maturation of the antibody layer (10-15 min); iii) continued adsorption and structural rearrangement of the layers to equilibrium.
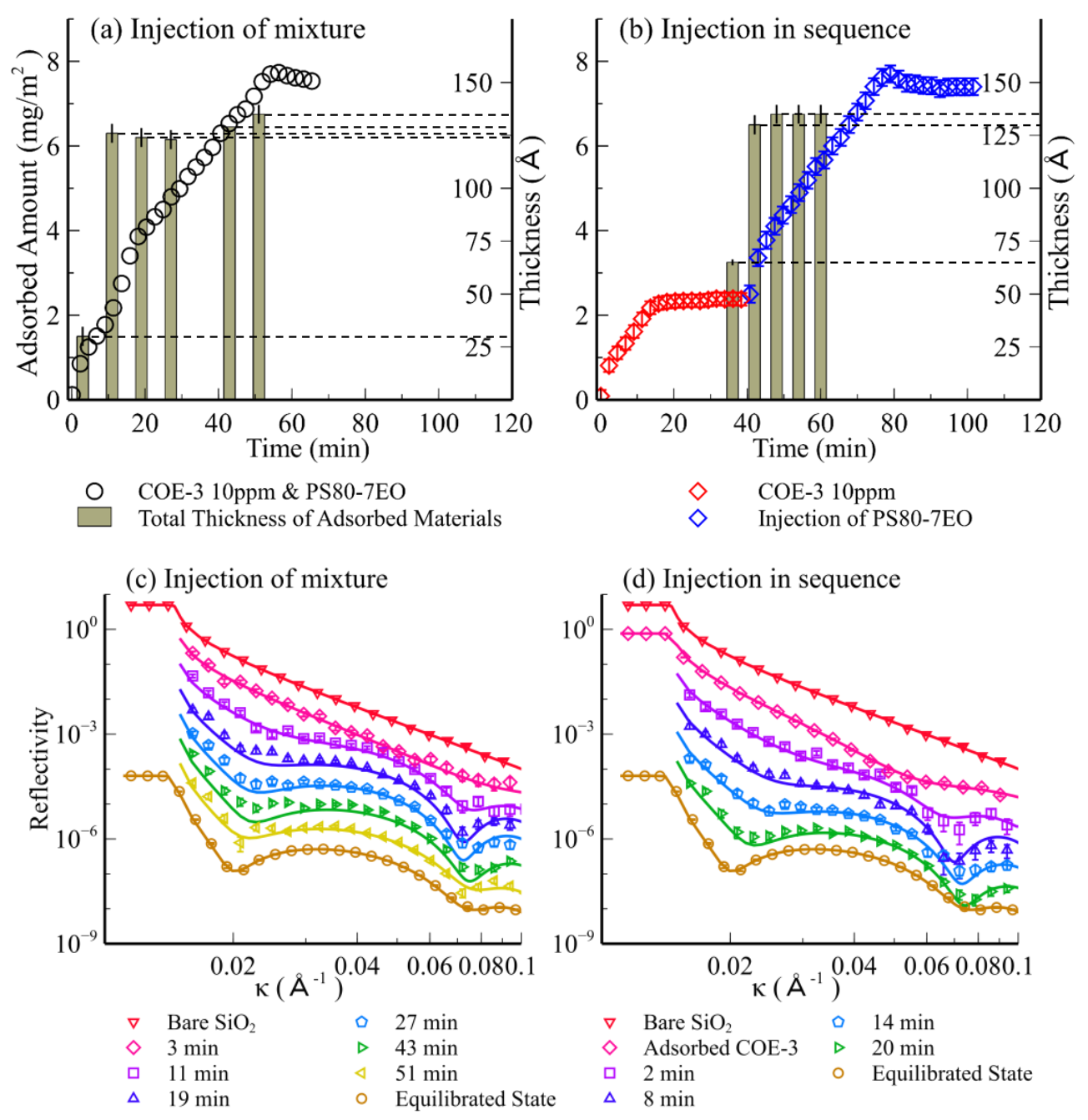

Figure 5. Surface adsorbed amount $(\Gamma)$ plotted against time measured by SE and thickness measured by NR (a and b) at the $\mathrm{SiO}_{2} /$ water interface for COE-3 with and without $0.2 \mathrm{mg} / \mathrm{ml} \mathrm{PS80-7EO} \mathrm{in} 25$ $\mathrm{mM}$ His buffer, $\mathrm{pH} 5.5$; (a) the black circles present the adsorption from the mixture of COE-3 and surfactant; (b) the red diamonds present the adsorption process of COE-3 alone followed by blue diamonds for the injection of surfactant. The thin bar charts present the total thickness of the adsorbed materials which was obtained from the dynamic NR measurements showed in Figure 5 (c) and (d). The profiles of the dynamic NR measurements at each time are plotted in (c) for the injection of the mixture of COE-3 and surfactant, and (d) for the injection of surfactant after COE-3 adsorption alone. The continuous lines denote the best fits. For clarity, the profiles were plotted with a $0.2^{\mathrm{n}}$ offset. The profiles plotted without offset are shown in Figure S6.

These results imply that in the pre-mixed solution, mAb and surfactant do not have strong affinity towards each other. Furthermore, the surfactants have little affinity for the surface, as 
in the case of surfactant adsorption alone (Figure S3), and similarly have little affinity for adsorbed $\mathrm{mAb}$ molecules in the initial phase of the dynamic process. However, as mAb adsorption reaches equilibrium at maximal surface packing, PS80-7EO does demonstrate an affinity for the mAb layer, implying exposure of hydrophobic patches due to structural rearrangement, albeit limited ( $c f$. COE-3 layer thicknesses in Table S3).

Whether mAb and surfactant are co- or sequentially-injected to the surface, similar amounts of material are adsorbed at equilibrium, and the component layer structures are also similar, evidenced by overlapping neutron reflectivity profiles (Figure S5). Thus, only by the use of multiple isotopic contrasts is it possible to unravel the component layer structures and their evolution over time.

\subsection{NR Data Analysis to Unravel the Co-adsorbed Layer Structure}

The combined SE and NR data above provide insight into the dynamic nature of the adsorbed layers and their structural evolution. To gain further characterization of the interfacial structure, the adsorbed layer at equilibration for co-adsorption of $0.01 \mathrm{mg} / \mathrm{ml} \mathrm{COE}-3$ with 0.2 $\mathrm{mg} / \mathrm{ml}$ HPS80-7EO/DPS80-7EO was measured by NR under CM2.58 and $\mathrm{D}_{2} \mathrm{O}$ contrasts. At CM2.58 the solution is matched to the COE-3, so the reflectivity is sensitive to the surfactant present. However, the inner layer did not significantly vary between $\mathrm{H}$ and $\mathrm{D}$ surfactant (which would have very different SLDs for the head group), indicating that there is very little surfactant head group present within this layer. Moreover, the average SLD of the inner layer is close to 2.58 while the surfactant tail group has an SLD of 0.39, showing that there are little surfactant tail groups present in the inner layer as well. Thus we assumed that the inner layer (adsorbed to the $\mathrm{SiO}_{2}$ surface) was predominantly occupied by COE-3 molecules. Under this assumption, the adsorbed amount of COE-3 was calculated by equation (5) and (6). This adsorbed amount is found to be similar to that for COE-3 adsorbed alone; the outer layer (exposed to solvent) must have been predominantly occupied by surfactant molecules.

It was found that whilst a 2-layer model could replicate most of the main features of the measured reflectivity profiles in the general shape and position of interference fringes for each contrast, there was a lack of precision and consistency. When adjustments were made at the interface between the inner mAb layer and outer surfactant layer and that between the surfactant layer and bulk water, the fits were significantly improved. Figure 6(a) shows the 4-layer fits with the matching calculated reflectivity profiles plotted as continuous lines and 
Figure 6(b) presents the best fitted SLDs from the 4 isotopic contrasts. It should be noted that the fitting was undertaken simultaneously and following the least-squared minimization process. Under each isotopic contrast, the SLD in each layer is coupled to the volume fraction of $\mathrm{mAb}$, surfactant and water. The simultaneous fitting ensured that the thickness and composition of each layer were consistent. However, minor deviations in SLD and thickness between contrasts in each layer were allowed for fitting optimization by achieving the minimal mean-squared errors for each contrast. The SLDs for mAb, the head and tail of deuterated and hydrogenated surfactants are given in Table S1. The best fitted values under each contrast and the average values are given in Table S2.
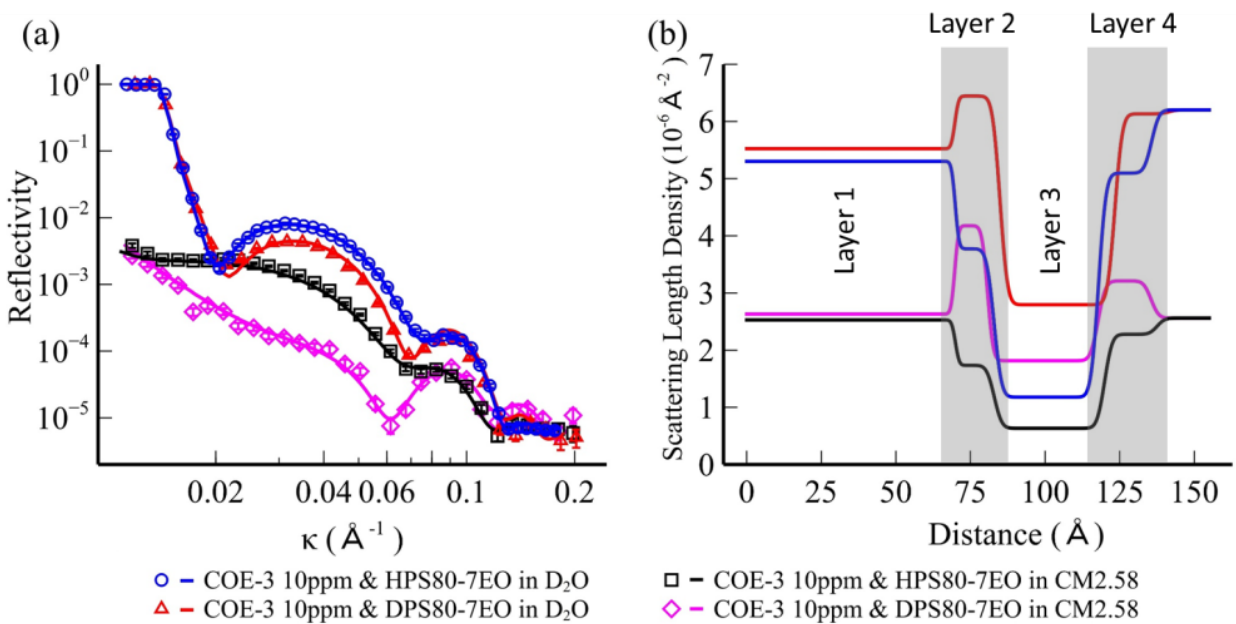

Figure 6. (a) $\mathrm{NR}$ profiles measured at the $\mathrm{SiO}_{2}$ surface for COE-3 adsorption at $0.01 \mathrm{mg} / \mathrm{ml}$ mixed with $0.2 \mathrm{mg} / \mathrm{ml}$ protonated and deuterated PS80-7EO in $\mathrm{D}_{2} \mathrm{O}$ and contrast matching COE-3 water under $\mathrm{pH} 5.5$ (25mM His buffer); the continuous lines denote the best fits of which the scattering length density plotted against the distance in (b). All fitting parameters showed in Table S2.

As evident from Figure 6(b), the optimal fitting indicates the slight thickening of the inner COE-3 layer (layer 1), above that obtained for the adsorbed COE-3 alone (70Å vs. $65 \AA$ ). The equilibrium adsorbed COE-3 layer alone can be fitted as a monolayer or, when taking into consideration relative changes in molecular orientation, as a 2-layer model comprised of a dense inner layer of $45 \AA$ with volume fraction $\left(\phi_{C O E-3}\right)=0.35$ and a sparse outer layer of 20 $\AA$ with $\phi_{C O E-3}=0.08$ (Figure $7(\mathrm{a})$ and Table 1), with the remaining volume fraction comprised of water. Models of COE-3-surfactant co-adsorption are complex, with 4 layers corresponding to COE-3, PS80-7EO, the COE-3/surfactant and surfactant/water interface (Figure 7); the COE-3 layer is $70 \AA$ with $\phi_{C O E-3}=0.25$ (Table S2), wherein the molecules are oriented upwards in respect of their long-axes relative to the surface. The fitted model indicates a clear surfactant binding to the $\mathrm{mAb}$. In regard of surfactant orientation: layer 2 is 
modeled as 12-13 $\AA$ thick comprised mainly of EO head groups, layer 3 is $36-38 \AA$ thick and comprised mainly of the aliphatic tails, layer 4 is $17-18 \AA$ thick and comprised mainly of head groups exposed to the bulk water (Figure 7). Thus, outer surfactant layer adsorbed to the inner mAb layer is self-assembled into a sandwiched bilayer.

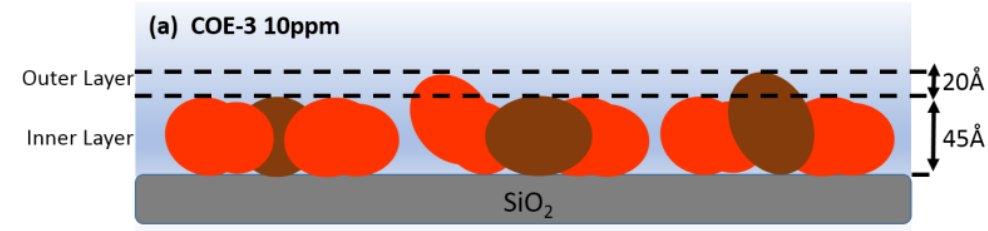

(b) COE-3 10ppm + 0.02\% PS80-7EO

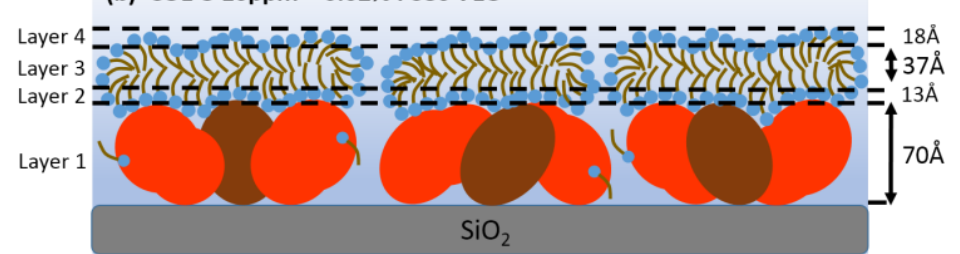

Figure 7. Schematic showed the adsorption of (a) COE-3 alone and (b) the structure of the compound layer of COE-3 and PS80-7EO. The light and dark red parts represent the Fc and Fab of COE-3.

The total adsorbed amount as determined from both SE and NR is shown in Figure 8. The NR measurements made under different isotopic contrasts enabled the determination of the distributions of COE-3, surfactant heads and tails across the interface; the bar chart in Figure 8 shows the amount of COE-3, surfactant heads and tails distributed in each layer, with the total amount consistent with the SE analysis. It is interesting to note that the number density ratio between the surfactant tail and head groups is about 1.1 (calculated from numbers in Table S2). This $10 \%$ error results from the structure variation in the parallel experiments of different isotopic contrasts and the inaccurate estimation of the average number of EO groups per surfactant molecule. To ensure the consistency of the structure between the parallel experiments under different isotopic contrasts, a simultaneous fitting with Bayesian analysis was also made using the software called Rascal. The fitting model in Rascal constrains the number densities of head groups equal to the tail groups and allows a structural variation between $\mathrm{H}$ and $\mathrm{D}$ surfactant. The obtained SLD profiles as presented in Figure S7 also suggested similar structure to that stated before, consisting of a clear COE-3 layer followed by a surfactant bilayer.

What the models cannot provide is an understanding of the initial low affinity binding event between surfactant and mAb layer and subsequent rearrangement into a bilayer; i.e. it 
remains unclear whether the binding was initiated through the aliphatic chain, or EO head group. Since PS80-20EO and $\mathrm{C}_{12} \mathrm{E}_{5}$ do not associate with the mAb layer, the strongest hydrophobicity of the nonionic surfactants may best predict the affinity of PS80-7EO for the mAb layer.

Interfacial adsorption of proteins has been studied extensively as the process underlines many technological applications. ${ }^{16}$ Protein adsorption at the bare $\mathrm{SiO}_{2} /$ water interface has been used as the model interface by our own and many other groups to ascertain how different proteins adsorb and desorb with and without surfactants. This is because silicon surfaces can be readily polished reproducibly with optically flat surface structure. The polished silicon surface bears a native oxide layer that offers surface properties similar to glass. In the context of this work, glass containers are amongst popular storage devices for future protein therapeutics. Hence, fundamental work on the adsorption of mAbs with and without surfactants is of direct relevance.

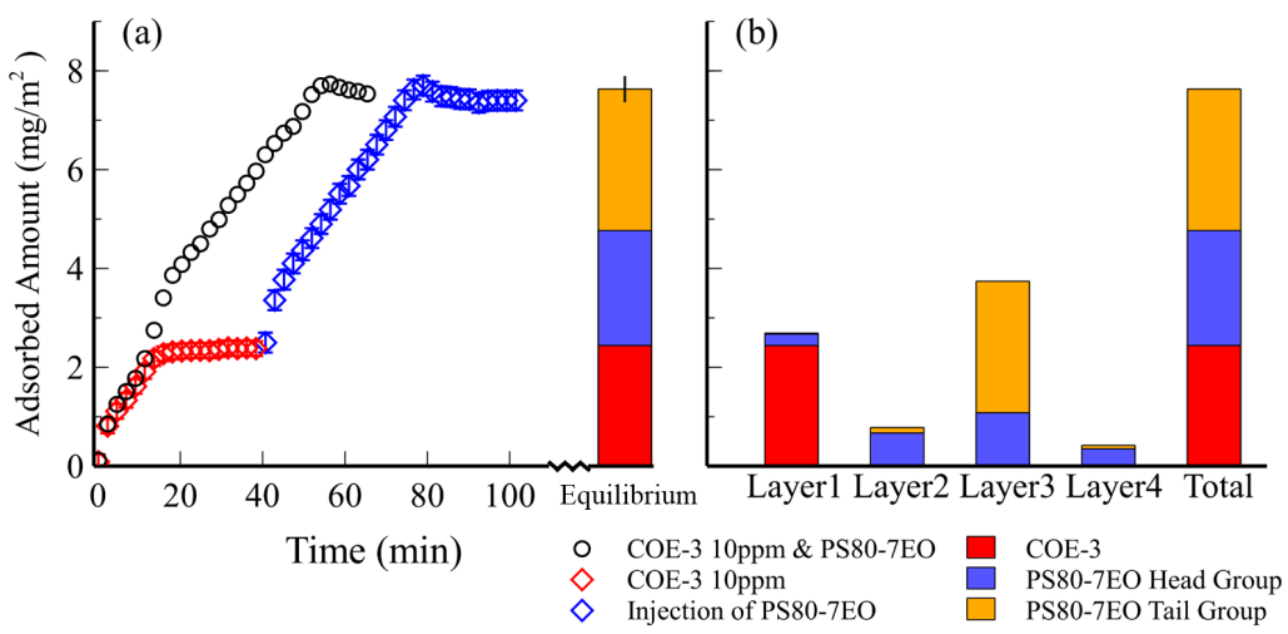

Figure 8. (a) The adsorbed amount by SE measured from co-adsorption (black) and sequence adsorption (red and blue) compared to the total adsorbed amount by NR measured at equilibrium; (b) The amount of COE-3, and the head and tail of PS80-7EO distributed in each sublayer and the total amount from the 4-layer model analysis as shown in Fig. 6. The bar charts denote the amount of COE-3 (red), surfactant head (blue) and tail.

We have previously studied protein adsorption at solid/water interfaces under different surface and solution conditions. Ionic surfactants such as anionic SDS and cationic $\mathrm{C}_{12} \mathrm{TAB}$ bind with proteins through electrostatic interaction. ${ }^{21,22}$ Depending on the exact molar ratio and solution environment ( $\mathrm{pH}$ and ionic strength) such ionic surfactant molecules may cause structural unfolding to protein molecules once bound electrostatically. These interactions often lead to the formation of complexes and even insoluble precipitates, thus complicating 
the intended studies. On the other hand, nonionic surfactants such as $\mathrm{C}_{12} \mathrm{E}_{5}$ usually do not show an affinity for protein molecules. At the air/water interface, $\mathrm{C}_{12} \mathrm{E}_{5}$ can replace proteins such as lysozyme and albumins because of their different surface physical activities. ${ }^{40}$ However, once lysozyme and albumins are adsorbed at the bare $\mathrm{SiO}_{2} /$ water interface, $\mathrm{C}_{12} \mathrm{E}_{5}$ cannot co-adsorb due to its low affinity associated with its relatively high hydrophilicity. ${ }^{22}$ Thus, the co-adsorption of COE-3 and $\mathrm{C}_{12} \mathrm{E}_{5}$ or PS80-20EO is very similar to the behaviour of BSA-C ${ }_{12} \mathrm{E}_{5}$ at the $\mathrm{SiO}_{2}$ /water interface, in that the presence of $\mathrm{C}_{12} \mathrm{E}_{5}$ or PS80-20EO did not perturb COE-3 adsorption, irrespective of the sequence of introduction to the surface. The effect of polysorbate head group size and alkyl chain length on the adsorption of hydrophobin (a highly surface active globular protein with distinct structural flexibility and hydrophobic patches) at the air/water interface has been studied by NR. ${ }^{27}$ It was revealed that whilst PS80-20EO displayed a weak affinity for hydrophobin, a decrease in the ethoxylate head group size increased affinity. Similarly, here we have shown that the relatively hydrophobic PS80-7EO has an affinity for the maximally packed, adsorbed COE-3 layer at equilibrium, implying hydrophobic interactions through structural rearrangement. Further binding of PS80-7EO ultimately results in self-assembly into a surfactant bilayer, to which no further mAb adsorbs.

\section{Conclusion}

Through combined SE and NR data analysis, a molecular level understanding of mAb adsorption at the $\mathrm{SiO}_{2}$ /water interface has been achieved that is relevant to the environment encountered by a mAb during formulation and fill-finish into glass container closures. Relatively hydrophilic nonionic surfactants such as PS80-20EO and $\mathrm{C}_{12} \mathrm{E}_{5}$ do not measurably adsorb to the glass/water interface; in this case, mAb adsorption proceeds rapidly unperturbed by co-addition of these surfactants at concentrations 10-fold above their CMC. The adsorbed $\mathrm{mAb}$ layer at equilibrium is hydrated but sufficiently packed to cause a shift in the orientation of the mAb longitudinal axes away from the surface. This mAb packing arrangement is associated with minor structural rearrangement that is sufficient for the relatively hydrophobic PS80-7EO (but not PS80-20EO and $\mathrm{C}_{12} \mathrm{E}_{5}$ ) to form a sparse surfactant bilayer at the $\mathrm{mAb} /$ water interface. The resultant $\mathrm{mAb}$-surfactant layer is robust and resistant to further adsorption events, at least at these mAb concentrations. Further studies would be required to 
understand how the model defined relates to concentrated $(100 \mathrm{mg} / \mathrm{ml}) \mathrm{mAb}$ formulations presented in a siliconized, prefilled syringe.

\section{Supporting Information}

The Supporting Information including dynamic adsorption from COE-3, the additional neutron reflection measurements on the binding of PS80-7EO into adsorbed CIE-3 layers and structural parameters obtained from the combined neutron data analysis is available free of charge on the ACS Publications webpage.

\section{Acknowledgements}

We thank funding support from MedImmune Ltd, neutron beam times on Reflectometer Inter awarded to undertake this work at ISIS Neutron Facility, Chilton, Didcot, under the support of STFC. ZL acknowledges studentship support from University of Manchester via an Overseas Research Scholarship (ORS) award and a physics research merit award. We also thank the support from a Marie Curie Fellowship ITN grant (grant number 608184) under SNAL (Small nano-objects for alteration of lipid-bilayers) and EPSRC for support under EP/F062966/1

\section{Author contributions}

JRL, CFW, RN and SMB conceived the project. ZL, FP and JRL designed and performed the experiments. RL, EP, XH, SR, DC, RJLW, JRPW, ZL and JRL contributed to neutron reflection measurements, data analysis and interpretation. PL and JRL discussed about the choices of nonionic surfactants and PL undertook the synthesis of deuterium labelled ones. ZL, FP, CFW and JRL wrote the manuscript. All authors reviewed the manuscript and approved its submission.

\section{References}


(1) Dempke, W. C. M.; Fenchel, K.; Uciechowski, P.; Dale, S. P. Second- and ThirdGeneration Drugs for Immuno-Oncology treatment-The More the Better? Eur. J. Cancer 2017, 74, 55-72.

(2) Yoo, J.-W.; Irvine, D. J.; Discher, D. E.; Mitragotri, S. Bio-Inspired, Bioengineered and Biomimetic Drug Delivery Carriers. Nat. Rev. Drug Discov. 2011, 10 (7), 521-535.

(3) Vacchelli, E.; Aranda, F.; Eggermont, A.; Galon, J.; Sautès-Fridman, C.; Zitvogel, L.; Kroemer, G.; Galluzzi, L. Trial Watch: Tumor-Targeting Monoclonal Antibodies in Cancer Therapy. Oncoimmunology 2014, 3 (1), e27048.

(4) Reichert, J. M. Antibodies to Watch in 2015. MAbs 2015, 7 (1), 1-8.

(5) Couston, R. G.; Skoda, M. W.; Uddin, S.; van der Walle, C. F. Adsorption Behavior of a Human Monoclonal Antibody at Hydrophilic and Hydrophobic Surfaces. MAbs 2013, $5(1), 126-139$.

(6) Perchiacca, J. M.; Ladiwala, A. R. A.; Bhattacharya, M.; Tessier, P. M. AggregationResistant Domain Antibodies Engineered with Charged Mutations near the Edges of the Complementarity-Determining Regions. Protein Eng. Des. Sel. 2012, 25 (10), 591602 .

(7) Perevozchikova, T.; Nanda, H.; Nesta, D. P.; Roberts, C. J. Protein Adsorption, Desorption, and Aggregation Mediated by Solid-Liquid Interfaces. J. Pharm. Sci. 2015, 104 (6), 1946-1959.

(8) Oom, A.; Poggi, M.; Wikström, J.; Sukumar, M. Surface Interactions of Monoclonal Antibodies Characterized by Quartz Crystal Microbalance with Dissipation: Impact of Hydrophobicity and Protein Self-Interactions. J. Pharm. Sci. 2012, 101 (2), 519-529.

(9) Härtl, E.; Dixit, N.; Besheer, A.; Kalonia, D.; Winter, G. Weak Antibody-cyclodextrin Interactions Determined by Quartz Crystal Microbalance and Dynamic/static Light Scattering. Eur. J. Pharm. Biopharm. 2013, 85 (3), 781-789.

(10) Kapp, S. J.; Larsson, I.; Van De Weert, M.; Cárdenas, M.; Jorgensen, L. Competitive Adsorption of Monoclonal Antibodies and Nonionic Surfactants at Solid Hydrophobic Surfaces. J. Pharm. Sci. 2015, 104 (2), 593-601.

(11) Hoehne, M.; Samuel, F.; Dong, A.; Wurth, C.; Mahler, H.-C.; Carpenter, J. F.; Randolph, T. W. Adsorption of Monoclonal Antibodies to Glass Microparticles. $J$. Pharm. Sci. 2011, 100 (1), 123-132.

(12) Shomali, M.; Tanriverdi, S.; Freitag, A. J.; Engert, J.; Winter, G.; Siedler, M.; Kaymakcalan, Z.; Carpenter, J. F.; Randolph, T. W. Dose Levels in ParticulateContaining Formulations Impact Anti-Drug Antibody Responses to Murine Monoclonal Antibody in Mice. J. Pharm. Sci. 2015, 104 (5), 1610-1621.

(13) Fathallah, A. M.; Chiang, M.; Mishra, A.; Kumar, S.; Xue, L.; Russell Middaugh, C.; Balu-Iyer, S. V. The Effect of Small Oligomeric Protein Aggregates on the Immunogenicity of Intravenous and Subcutaneous Administered Antibodies. J. Pharm. Sci. 2015, 104 (11), 3691-3702.

(14) Smith, C.; Li, Z.Y.; Holman, R.; Pan, F.; Campbell, R.A.; Campana, M.; Li, P.; Webster, J.R.P.; Bishop, S.M.; Narwal, R.; Uddin, S.; van der Walle, C. F.; Lu, J. R. Antibody Adsorption on the Surface of Water Studied by Neutron Reflection. MAbs 2017, 9 (3), 466-475.

(15) Fainerman, V. B.; Lotfi, M.; Javadi, A.; Aksenenko, E. V.; Tarasevich, Y. I.; Bastani, 
D.; Miller, R. Adsorption of Proteins at the Solution/Air Interface Influenced by Added Nonionic Surfactants at Very Low Concentrations for Both Components. 2. Effect of Different Surfactants and Theoretical Model. Langmuir 2014, 30 (43), $12812-12818$.

(16) Lu, J.R.; Zhao, X.B.; Yaseen, M. Protein Adsorption Studied by Neutron Reflection. Curr. Opin. Colloid Interface Sci. 2007, 12 (1), 9-16.

(17) Li, Z.Y.; Li, R.H.; Smith, C.; Pan, F.; Campana, M.; Webster, J.R.P.; van der Walle, C.F.; Uddin, S.; Bishop, S.M.; Narwal, R.; Warwicker, J.; Lu, J.R. Neutron Reflection Study of Surface Adsorption of Fc, Fab, and the Whole mAb. ACS Appl. Mater. Interfaces 2017, 9 (27), 23202-23211.

(18) Zhao, X.; Pan, F.; Cowsill, B.; Lu, J.R.; Garcia-Gancedo, L.; Flewitt, A.J.; Ashley, G. M.; Luo, J. Interfacial Immobilization of Monoclonal Antibody and Detection of Human Prostate-Specific Antigen. Langmuir 2011, 27 (12), 7654-7662.

(19) Zhao, X.B.; Pan, F.; Garcia-Gancedo, L.; Flewitt, A. J.; Ashley, G.M.; Luo, J.; Lu, J.R. Interfacial Recognition of Human Prostate-Specific Antigen by Immobilized Monoclonal Antibody: Effects of Solution Conditions and Surface Chemistry. J. $R$. Soc. Interface 2012, 9 (75), 2457-2467.

(20) Xu, H.; Zhao, X.; Grant, C.; Lu, J.R.; Williams, D.E.; Penfold, J. Orientation of a Monoclonal Antibody Adsorbed at the Solid/Solution Interface: A Combined Study Using Atomic Force Microscopy and Neutron Reflectivity. Langmuir 2006, 22 (14), 6313-6320.

(21) Lu, J.R.; Su, T.J.; Thomas, R.K. Binding of Surfactants onto Preadsorbed Layers of Bovine Serum Albumin at the Silica-Water Interface. J. Phys. Chem. B 1998, 102 (50), 10307-10315.

(22) Lu, J.R.; Su, T.J.; Thomas, R.K.; Penfold, J. Binding of Sodium Dodecyl Sulfate to Bovine Serum Albumin Layers Adsorbed at the Silica-Water Interface. Langmuir 1998, 14 (21), 6261-6268.

(23) Tamada, T.; Shinmi, D.; Ikeda, M.; Yonezawa, Y.; Kataoka, S.; Kuroki, R.; Mori, E.; Motoki, K. TRAIL-R2 Superoligomerization Induced by Human Monoclonal Agonistic Antibody KMTR2. Sci. Rep. 2016, 5 (1), 17936.

(24) Krapp, S.; Mimura, Y.; Jefferis, R.; Huber, R.; Sondermann, P. Structural Analysis of Human IgG-Fc Glycoforms Reveals a Correlation Between Glycosylation and Structural Integrity. J. Mol. Biol. 2003, 325 (5), 979-989.

(25) Roberts, D.; Keeling, R.; Tracka, M.; van der Walle, C. F.; Uddin, S.; Warwicker, J.; Curtis, R. The Role of Electrostatics in Protein-Protein Interactions of a Monoclonal Antibody. Mol. Pharm. 2014, 11 (7), 2475-2489.

$$
\text { Pan, F.; Li, Z.Y.; Leyshon, T.; Rouse, D.; Li, R.H.; Smith, C.; Campana, M.; }
$$

Webster, J.R.P.; Bishop, S.M.; Narwal, R.; van der Walle, C.F.; Warwicker, J.; Lu, J.R. Interfacial Adsorption of Monoclonal Antibody COE3 at the Solid/water Interface, ACS Appl.

Mater. Interface 2018, 10, 1306-1316. DOI: 10.1021/acsami.7b13332.

(27) Penfold, J.; Thomas, R.K.; Li, P.; Petkov, J.T.; Tucker, I.; Cox, A.R.; Hedges, N.; Webster, J.R.P.; Skoda, M.W.A. Impact of the Degree of Ethoxylation of the 
Ethoxylated Polysorbate Nonionic Surfactant on the Surface Self-Assembly of Hydrophobin-Ethoxylated Polysorbate Surfactant Mixtures. Langmuir 2014, 30 (32), 9741-9751.

(28) Griffin, W. . Calculation of HLB Values of Non-Ionic Surfactants. J. Soc. Cosmet. Chem 1954, 5 (4), 249-256.

(29) Pan, F.; Zhao, X.; Perumal, S.; Waigh, T.A.; Lu, J.R.; Webster, J.R.P. Interfacial Dynamic Adsorption and Structure of Molecular Layers of Peptide Surfactants. Langmuir 2010, 26 (8), 5690-5696.

(30) De Feijter, J.A.; Benjamins, J.; Veer, F. A. Ellipsometry as a Tool to Study the Adsorption Behavior of Synthetic and Biopolymers at the Air-Water Interface. Biopolymers 1978, 17 (7), 1759-1772.

(31) Su, T.J.; Lu, J.R.; Thomas, R.K.; Cui, Z.F.; Penfold, J. The Effect of Solution pH on the Structure of Lysozyme Layers Adsorbed at the Silica-Water Interface Studied by Neutron Reflection. Langmuir 1998, 14 (2), 438-445.

(32) Peterson, P. F.; Campbell, S.I.; Reuter, M.A.; Taylor, R.J.; Zikovsky, J. Event-Based Processing of Neutron Scattering Data. Nucl. Instruments Methods Phys. Res. Sect. A Accel. Spectrometers, Detect. Assoc. Equip. 2015, 803, 24-28.

(33) Arnold, O.; Bilheux, J.C.; Borreguero, J.M.; Buts, A.; Campbell, S.I.; Chapon, L.; Doucet, M.; Draper, N.; Ferraz Leal, R.; Gigg, M.A.; Lynch, V.E.; Markvardsen, A.; Mikkelson, D.J.; Mikkelson, R.L.; Miller, R.; Palmen, K.; Parker, P.; Passos, G.; Perring, T.G.; Peterson, P.F.; Ren, S.; Reuter, M.A.; Savici, A. T.; Taylor, J.W.; Taylor, R.J.; Tolchenov, R.; Zhou, W.; Zikovsky, J. Mantid-Data analysis and visualization package for neutron scattering and $\mu$ SR experiments. Nuclear Inst. Methods in Physics Research, A 2014, 764, 156-166.

(34) Nelson, A. Co-Refinement of Multiple-Contrast neutron/X-Ray Reflectivity Data Using MOTOFIT. J. Appl. Crystallogr. 2006, 39 (2), 273-276.

(35) Lu, J.R.; Thomas, R.K. Neutron Reflection from Wet Interfaces. J. Chem. Soc. Faraday Trans. 1998, 94 (8), 995-1018.

(36) Lu, J.R.; Thomas, R.K.; Penfold, J. Surfactant Layers at the Air/water Interface: Structure and Composition. Adv. Colloid Interface Sci. 2000, 84 (1-3), 143-304.

(37) Tiberg, F. Physical Characterization of Non-Ionic Surfactant Layers Adsorbed at Hydrophilic and Hydrophobic Solid Surfaces by Time-Resolved Ellipsometry. $J$. Chem. Soc. Faraday Trans. 1996, 92 (4), 531.

(38) Penfold, J.; Staples, E.; Tucker, I. On the Consequences of Surface Treatment on the Adsorption of Nonionic Surfactants at the Hydrophilic Silica-Solution Interface. Langmuir 2002, 18 (8), 2967-2970.

(39) Henderson, J.A.; Richards, R.W.; Penfold, J.; Thomas, R.K. Neutron Reflectometry Using the Kinematic Approximation and Surface Quasi-Elastic Light Scattering from Spread Films of Poly(methyl Methacrylate). Macromolecules 1993, 26 (1), 65-75.

(40) Green, R.J.; Su, T.J.; Lu, J.R.; Webster, J.; Penfold, J. Competitive Adsorption of Lysozyme and $\mathrm{C}_{12} \mathrm{E}_{5}$ at the Air/liquid Interface. Phys. Chem. Chem. Phys. 2000, 2 (22), $5222-5229$. 
TOC:

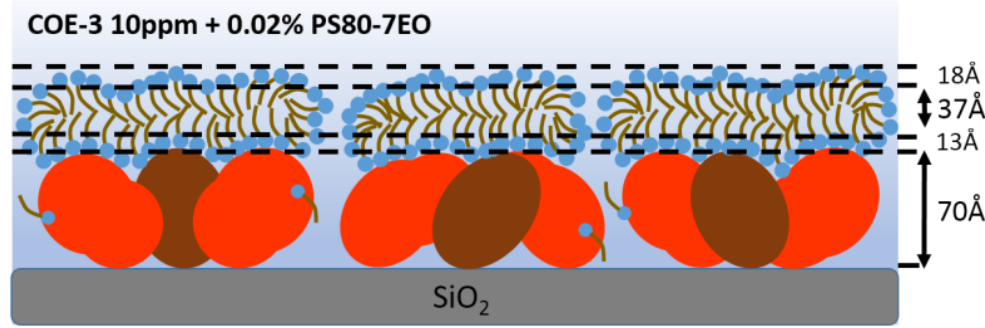




\title{
Supporting Information
}

\section{Co-adsorption of a Monoclonal Antibody and Nonionic Surfactant at the $\mathrm{SiO}_{2} /$ water Interface}

\author{
Zongyi $\mathrm{Li}^{1}$, Fang $\mathrm{Pan}^{1}$, Ruiheng $\mathrm{Li}^{1}$, Elias Pambou ${ }^{1}$, Xuzhi Hu${ }^{1}$, Sean Ruane ${ }^{1}$, Daniela \\ Ciumac ${ }^{1}$, Peixun $\mathrm{Li}^{2}$, Rebecca J L Welbourn ${ }^{2}$, John R P Webster ${ }^{2}$, Steven M. Bishop ${ }^{4}$, \\ Rojaramani Narwal ${ }^{4}$, Christopher F van der Walle ${ }^{3}$, Jian R Lu ${ }^{1}$
}

${ }^{1}$ Biological Physics Laboratory, School of Physics and Astronomy, University of Manchester, Oxford Road, Schuster Building, Manchester M13 9PL, UK.

${ }^{2}$ ISIS Neutron Facility, STFC, Chilton, Didcot OX11 0QZ, UK.

${ }^{3}$ Formulation Sciences, MedImmune Ltd, Sir Aaron Klug Building, Granta Park, Cambridge CB21 6GH, UK

${ }^{4}$ Formulation Sciences, MedImmune LLC, Gaithersburg, MD 20878, USA.

Corresponding author: Jian $\mathrm{R} \mathrm{Lu}$

(email: j.lu@manchester.ac.uk; Tel: +44 161 2003926)

ZL and FP made equal contributions 


\section{Section 1:}

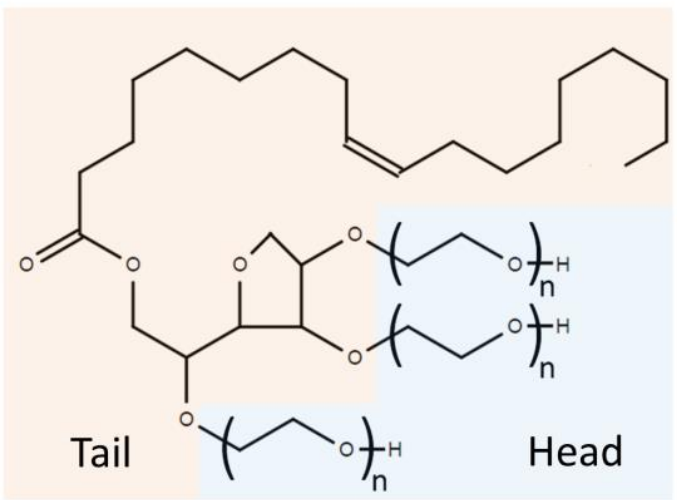

Figure S1. The molecular structure of PS80 (shown in hydrogenated form): with the total values of $n$ equal to about 20 for PS80-20EO and 7 for PS80-7EO. In this work, the PS80 head only refers to the polyethoxylated chains which have been fully deuterated for D-PS80.

The PS80 tail part includes the oleic acid chain and the sorbitan residue which remain protonated for both H-PS80 and D-PS80.

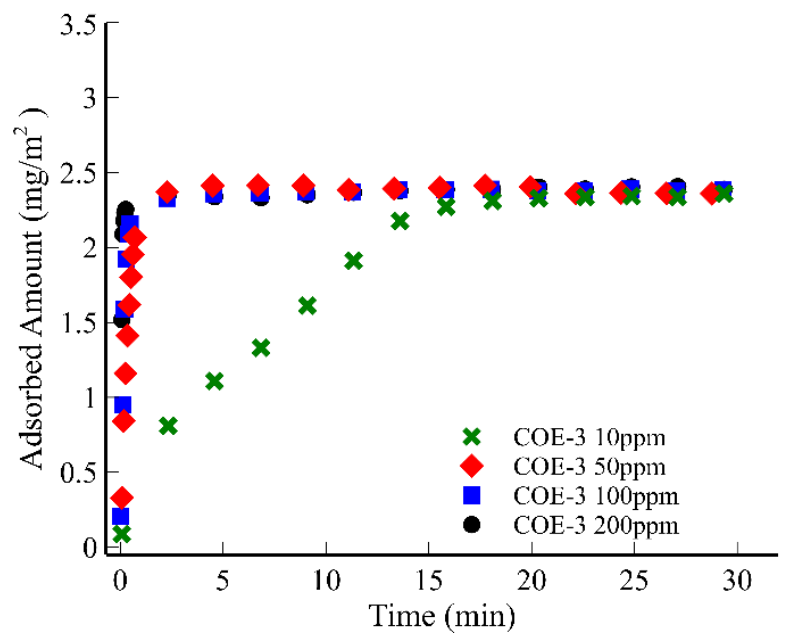

Figure S2. SE measurements of the surface adsorbed amount of COE-3 plotted against time at the $\mathrm{SiO}_{2}$ /water interface, in $25 \mathrm{mM}$ His buffer, $\mathrm{pH}$ 5.5, at concentrations as indicated. 

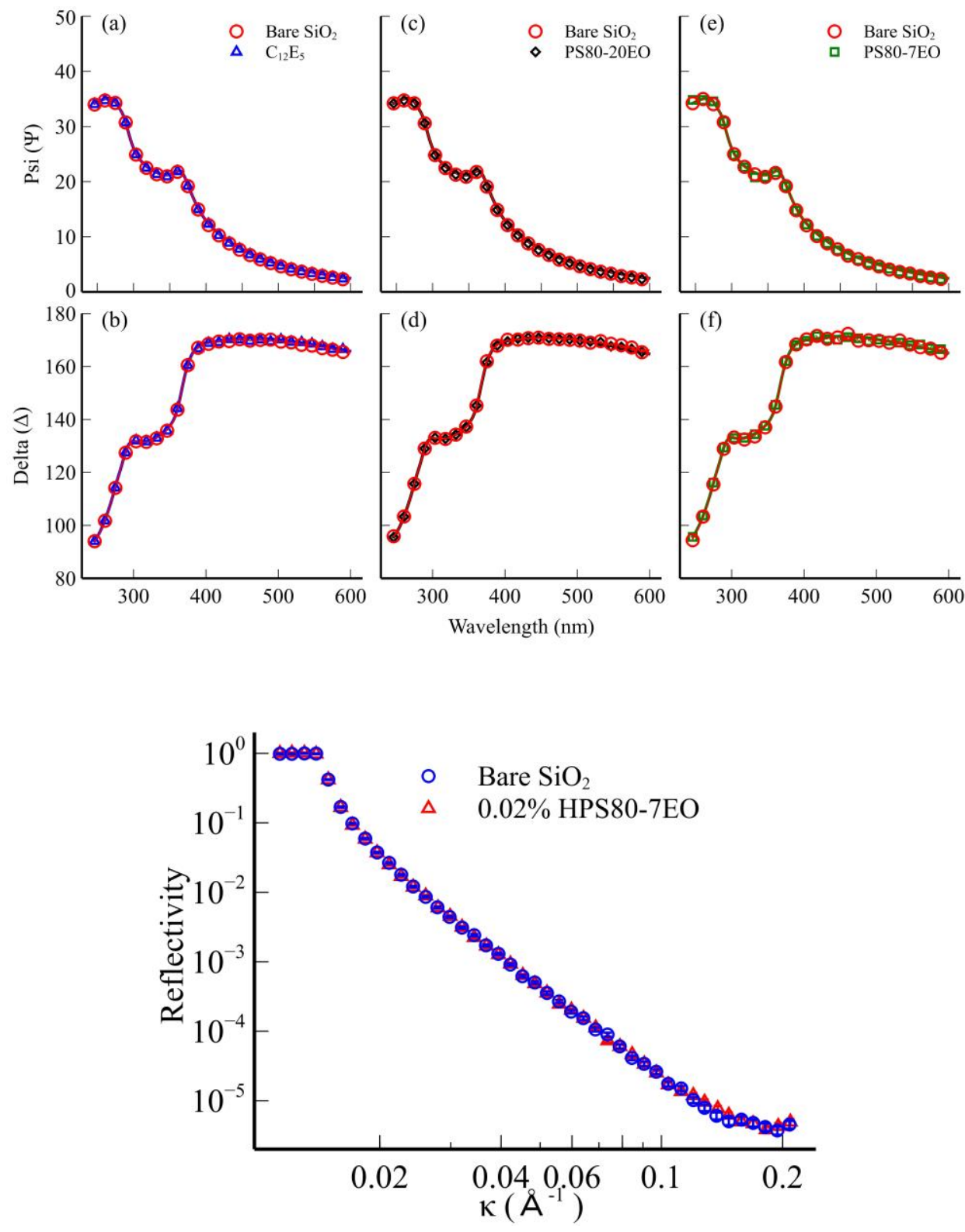

Figure S3. (Top) Ellipsometric scans of the amplitude component $\Psi$ and the phase difference $\Delta$ against wavelength measured at the $\mathrm{SiO}_{2}$ /water interface for $\mathrm{C}_{12} \mathrm{E}_{5}$ at $10 \times \mathrm{CMC}$ (a and b), $0.2 \mathrm{mg} / \mathrm{ml} \mathrm{PS80-20EO} \mathrm{(c} \mathrm{and} \mathrm{d)} \mathrm{and} 0.2 \mathrm{mg} / \mathrm{ml} \mathrm{PS80-7EO} \mathrm{(e} \mathrm{and} \mathrm{f)} \mathrm{in} 25 \mathrm{mM}$ His buffer, $\mathrm{pH}$ 5.5. The red circles present the data measured from bare $\mathrm{SiO}_{2} /$ water interface. (Bottom) NR profiles measured at the $\mathrm{SiO}_{2} / \mathrm{D}_{2} \mathrm{O}$ interface with and without $0.2 \mathrm{mg} / \mathrm{ml} \mathrm{HPS80-7EO}$; the almost identical reflectivity profiles indicate little surfactant adsorption at the interface. 

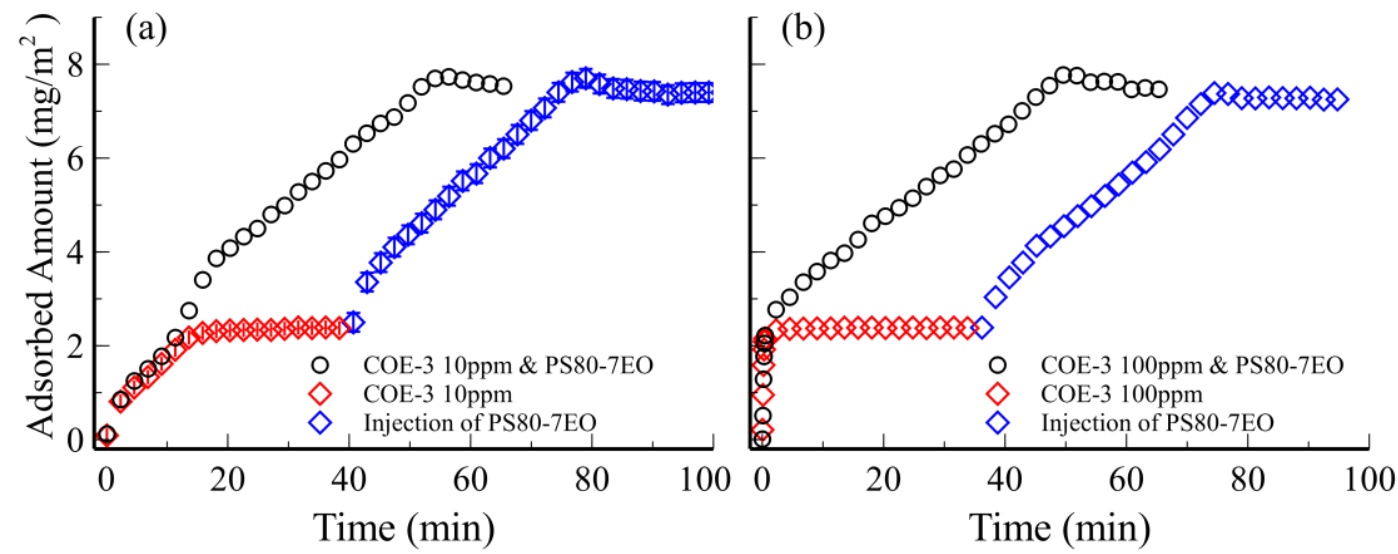

Figure S4. Surface adsorbed amount $(\Gamma)$ plotted against time measured by SE at the $\mathrm{SiO}_{2} /$ water interface for COE-3 (a) $0.01 \mathrm{mg} / \mathrm{ml}$ and (b) $0.1 \mathrm{mg} / \mathrm{ml}$ with and without 0.2 $\mathrm{mg} / \mathrm{ml} \mathrm{HPS80-7EO}$ in $25 \mathrm{mM}$ His buffer, $\mathrm{pH}$ 5.5. The red diamonds present the adsorption process of COE-3 alone followed by blue diamonds for the injection of surfactants, while the black circles present the adsorption from the mixture of COE-3 and surfactant.

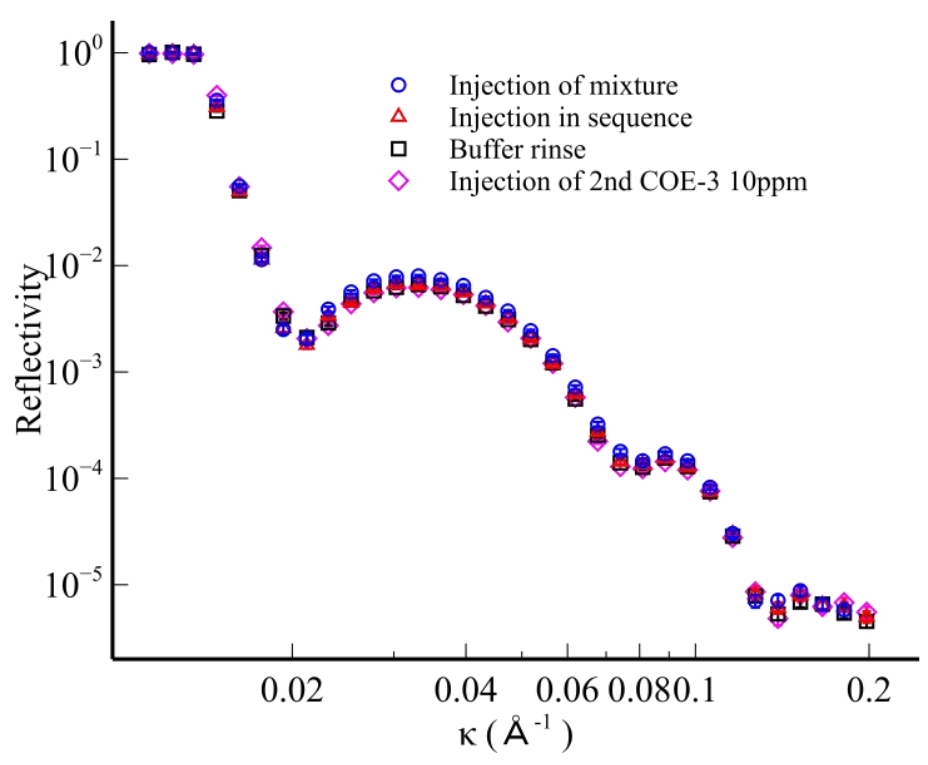

Figure S5. NR profiles measured at the $\mathrm{SiO}_{2} / \mathrm{D}_{2} \mathrm{O}$ interface for the layer of COE-3 and PS80-7EO formed by the injection of the mixture (blue circles) or injection in sequence (red triangles). The other NR profiles measured for the formed mixed layer after a rinse of buffer (black squares) and the second injection of $0.01 \mathrm{mg} / \mathrm{ml} \mathrm{COE-3} \mathrm{(magenta} \mathrm{diamonds)} \mathrm{are} \mathrm{also}$ shown for comparison. The closely overlapping reflectivity profiles indicate the high level of robustness of the layers once formed. 
(a) Injection in sequence

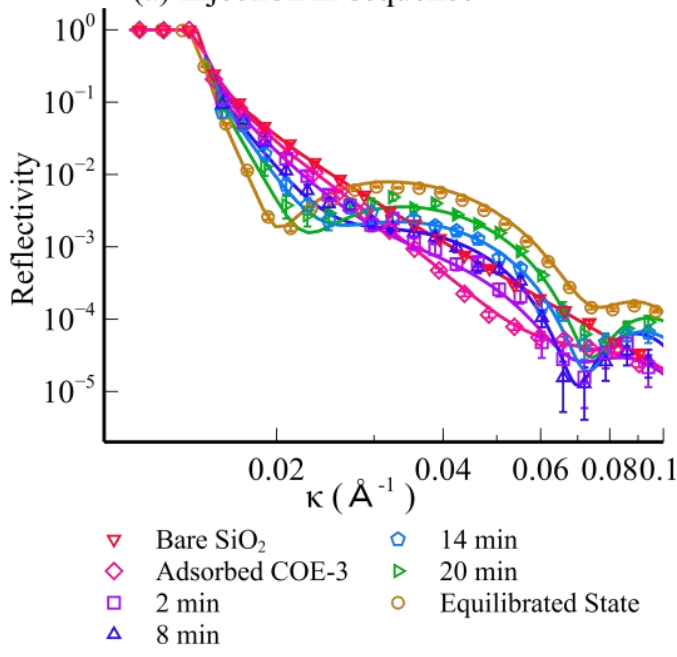

(b) Injection of mixture

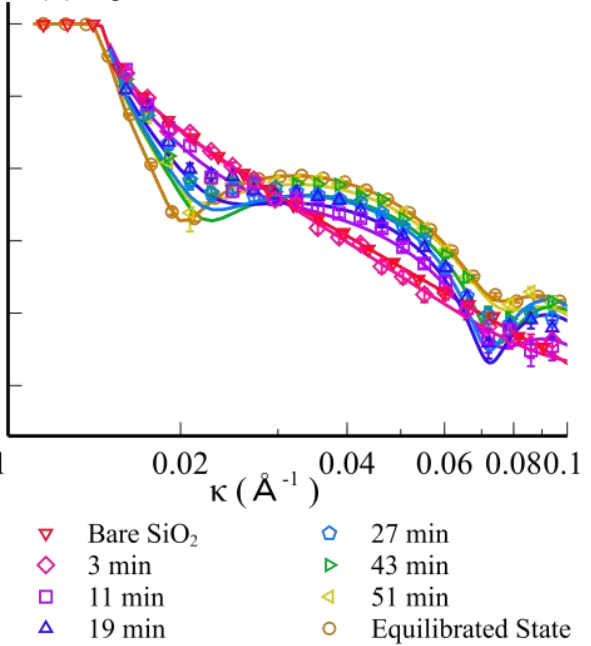

Figure S6. The profiles of the dynamic NR measurements at different times plotted without any offset in (a) the injection of surfactants after COE-3 adsorbed alone and (b) the injection of the mixture of COE-3 and surfactant. The continuous lines denote the best fits with key structural parameters listed in Table S3.
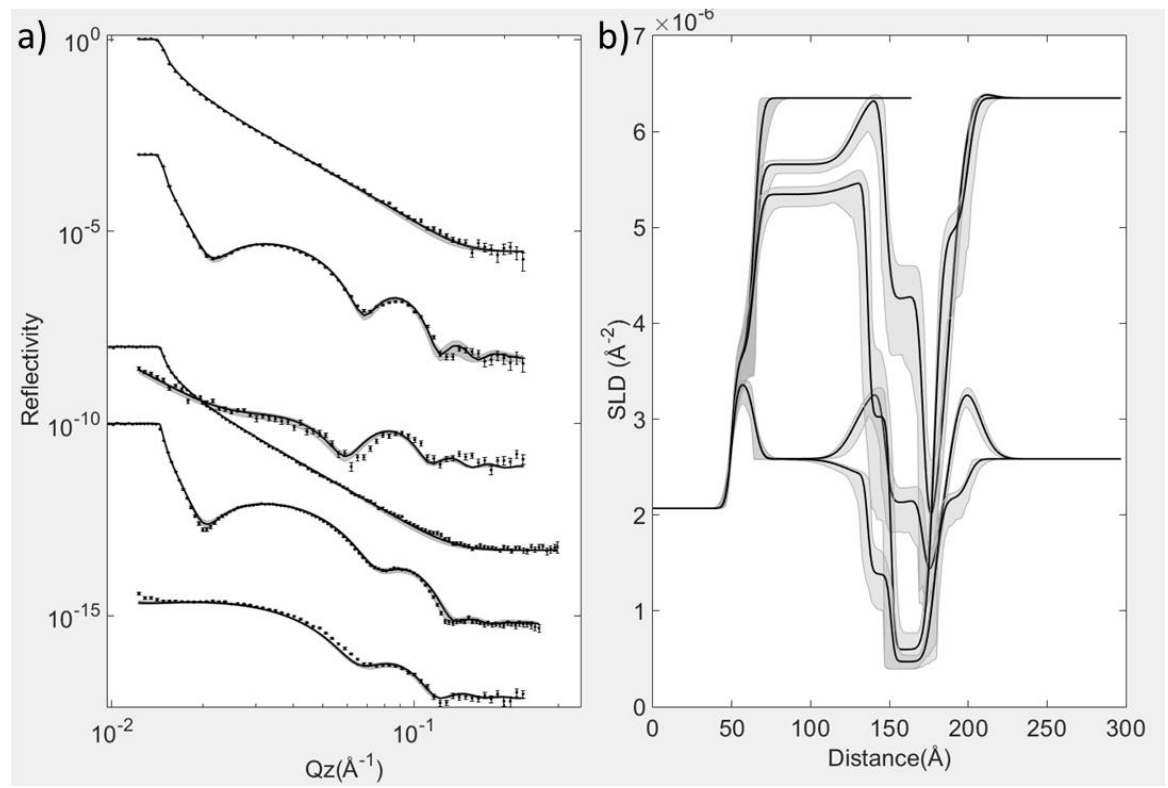

Figure S7. (a) NR profiles measured at the $\mathrm{SiO}_{2} /$ water interface for $\mathrm{COE}-3$ adsorption at 0.01 $\mathrm{mg} / \mathrm{ml}$ mixed with $0.2 \mathrm{mg} / \mathrm{ml}$ protonated and deuterated PS80-7EO in $\mathrm{D}_{2} \mathrm{O}$ and contrast matching COE-3 water (CM2.58) under pH 5.5 (25mM His buffer); the continuous lines denote the best fits using Rascal, of which the scattering length density plotted against the distance in (b). The grey areas highlight the possible range of fitting in a Bayesian analysis. All best fitted parameters are shown in Table S4. 


\begin{tabular}{|c|c|c|c|c|c|}
\hline Component & Contrast & $\begin{array}{c}S \boldsymbol{L} \\
/ 10^{-5} \AA\end{array}$ & $\begin{array}{c}\boldsymbol{S L D} \\
/ 10^{-6} \AA^{-2}\end{array}$ & $\begin{array}{l}\text { Vol } \\
/ \AA^{3}\end{array}$ & $\begin{array}{c}\boldsymbol{M W} \\
\operatorname{lgmol}^{-1}\end{array}$ \\
\hline \multirow{2}{*}{ COE-03 } & CM2.58 & 44345 & 2.58 & \multirow{2}{*}{171740} & 145912 \\
\hline & $\mathrm{D}_{2} \mathrm{O}$ & 57648 & 3.36 & & 147213 \\
\hline \multirow{2}{*}{$\begin{array}{c}\text { H-polysorbate } 80 \\
\text { head }\end{array}$} & CM2.58 & 49.30 & 1.06 & \multirow{2}{*}{465} & 360.7 \\
\hline & $\mathrm{D}_{2} \mathrm{O}$ & 66.40 & 1.43 & & 362.4 \\
\hline \multirow{2}{*}{$\begin{array}{c}\text { D-polysorbate } 80 \\
\text { head }\end{array}$} & CM2.58 & 340.80 & 7.33 & \multirow{2}{*}{465} & 388.9 \\
\hline & $\mathrm{D}_{2} \mathrm{O}$ & 357.80 & 7.70 & & 390.6 \\
\hline \multirow{2}{*}{ polysorbate 80 tail } & CM2.58 & 23.66 & 0.39 & \multirow{2}{*}{605} & 377.6 \\
\hline & $\mathrm{D}_{2} \mathrm{O}$ & 23.66 & 0.39 & & 377.6 \\
\hline
\end{tabular}

Table S1. The scattering length (SL), scattering length density (SLD, $\rho$ ), volume (V) and molecular weight (MW) of COE-3 and hydrogenated tail and deuterated (D-) and hydrogenated (H-) ethoxylate heads of PS80-7EO used for the model fitting to neutron reflectivity in $\mathrm{D}_{2} \mathrm{O}$ and contrast matched to COE-3 (CM2.58). 
(a) Best fitted parameters under individual contrasts

\begin{tabular}{|c|c|c|c|c|c|c|c|}
\hline & Contrast & $\begin{array}{c}S L D / 10^{-6} \AA^{-2} \\
\pm 0.1\end{array}$ & $d \AA$ & $\begin{array}{l}\phi_{C O E-3} \\
\pm 0.04\end{array}$ & $\begin{array}{r}\phi_{\text {head }} \\
\pm 0.04\end{array}$ & $\begin{array}{r}\phi_{\text {tail }} \\
\pm 0.04\end{array}$ & $\begin{array}{l}\boldsymbol{\phi}_{\text {water }} \\
\pm 0.04\end{array}$ \\
\hline \multirow{4}{*}{$\begin{array}{c}\text { Layer } \\
1\end{array}$} & HPS80-7EO in $\mathrm{D}_{2} \mathrm{O}$ & 5.4 & $70 \pm 2$ & 0.25 & 0.04 & 0 & 0.71 \\
\hline & DPS80-7EO in $\mathrm{D}_{2} \mathrm{O}$ & 5.5 & $70 \pm 2$ & 0.25 & 0.04 & 0 & 0.71 \\
\hline & HPS80-7EO in CM2.58 & 2.5 & $70 \pm 2$ & 0.25 & 0.04 & 0 & 0.71 \\
\hline & DPS80-7EO in CM2.58 & 2.6 & $70 \pm 2$ & 0.25 & 0.04 & 0 & 0.71 \\
\hline \multirow{4}{*}{$\begin{array}{l}\text { Layer } \\
2\end{array}$} & HPS80-7EO in $\mathrm{D}_{2} \mathrm{O}$ & 3.8 & $13 \pm 1$ & 0 & 0.41 & 0.08 & 0.51 \\
\hline & DPS80-7EO in $\mathrm{D}_{2} \mathrm{O}$ & 6.4 & $15 \pm 1$ & 0 & 0.40 & 0.06 & 0.54 \\
\hline & HPS80-7EO in CM2.58 & 1.7 & $13 \pm 1$ & 0 & 0.42 & 0.09 & 0.49 \\
\hline & DPS80-7EO in CM2.58 & 4.2 & $11 \pm 1$ & 0 & 0.38 & 0.09 & 0.53 \\
\hline \multirow{4}{*}{$\begin{array}{c}\text { Layer } \\
3\end{array}$} & HPS80-7EO in $\mathrm{D}_{2} \mathrm{O}$ & 1.2 & $35 \pm 2$ & 0 & 0.23 & 0.68 & 0.09 \\
\hline & DPS80-7EO in $\mathrm{D}_{2} \mathrm{O}$ & 2.8 & $38 \pm 2$ & 0 & 0.25 & 0.65 & 0.10 \\
\hline & HPS80-7EO in CM2.58 & 0.6 & $37 \pm 2$ & 0 & 0.25 & 0.72 & 0.03 \\
\hline & DPS80-7EO in CM2.58 & 1.8 & $37 \pm 2$ & 0 & 0.19 & 0.75 & 0.06 \\
\hline \multirow{4}{*}{$\begin{array}{c}\text { Layer } \\
4\end{array}$} & HPS80-7EO in $\mathrm{D}_{2} \mathrm{O}$ & 5.1 & $18 \pm 1$ & 0 & 0.17 & 0.05 & 0.78 \\
\hline & DPS80-7EO in $\mathrm{D}_{2} \mathrm{O}$ & 6.1 & $18 \pm 1$ & 0 & 0.15 & 0.05 & 0.80 \\
\hline & HPS80-7EO in CM2.58 & 2.3 & $18 \pm 1$ & 0 & 0.15 & 0.03 & 0.82 \\
\hline & DPS80-7EO in CM2.58 & 3.2 & $18 \pm 1$ & 0 & 0.15 & 0.03 & 0.82 \\
\hline
\end{tabular}

(b) Summary of the best fitted parameters for each of the sublayers

\begin{tabular}{|c|c|c|c|c|c|c|c|}
\hline & $\tau / \AA$ & $\begin{array}{c}\phi_{\text {COE-3 }} \\
\pm 0.04\end{array}$ & $\begin{array}{c}\Gamma_{\text {COE-3 }} \\
m g m^{-2}\end{array}$ & $\begin{array}{c}\phi_{\text {head }} \\
\pm 0.04\end{array}$ & $\begin{array}{c}\Gamma_{\text {head }} \\
m g m^{-2}\end{array}$ & $\begin{array}{c}\phi_{\text {tail }} \\
\pm 0.04\end{array}$ & $\begin{array}{c}\Gamma_{\text {tail }} \\
m g m^{-2}\end{array}$ \\
\hline Layer 1 & $70 \pm 2$ & 0.25 & $2.44 \pm 0.05$ & 0.04 & $0.23 \pm 0.02$ & 0 & 0 \\
\hline Layer 2 & $13 \pm 2$ & 0 & 0 & 0.40 & $0.67 \pm 0.10$ & 0.08 & $0.11 \pm 0.02$ \\
\hline Layer 3 & $37 \pm 2$ & 0 & 0 & 0.23 & $1.08 \pm 0.07$ & 0.70 & $2.66 \pm 0.18$ \\
\hline Layer 4 & $18 \pm 1$ & 0 & 0 & 0.15 & $0.35 \pm 0.02$ & 0.04 & $0.07 \pm 0.01$ \\
\hline Sum & $138 \pm 4$ & & $2.44 \pm 0.05$ & & $2.33 \pm 0.15$ & & $2.86 \pm 0.18$ \\
\hline
\end{tabular}

Table S2. Structural parameters obtained from the best fits to the adsorbed mAb layers in NR profiles measured under 4 contrasts from co-adsorption from the mixed solution of COE3 at $0.01 \mathrm{mg} / \mathrm{ml}$ and PS80-7EO at $0.2 \mathrm{mg} / \mathrm{ml}$ in His $25 \mathrm{mM}$ buffer, $\mathrm{pH} 5.5$. (a) Best fitted parameters under individual contrasts and (b) The average of best fitted parameters for each of the sublayers. H/D indicates head hydrogenated and head deuterated PS80-7EO used. 


\begin{tabular}{|c|c|c|c|c|}
\hline \multicolumn{5}{|c|}{ (a) Injection in Sequence } \\
\hline $\begin{array}{l}\text { Time } \\
(\min )\end{array}$ & Layer & $\begin{array}{l}S L D \pm 0.1 \\
\left(10^{-6} \AA^{-2}\right)\end{array}$ & $\begin{array}{c}\text { Thickness } \\
\pm 2(\AA)\end{array}$ & $\begin{array}{c}\text { Total } \\
\text { Thickness }\end{array}$ \\
\hline \multirow{2}{*}{0} & Layer 1 & 5.2 & 45 & \multirow{2}{*}{65} \\
\hline & Layer 2 & 6.1 & 20 & \\
\hline \multirow{2}{*}{2} & Layer 1 & 5.2 & 40 & \multirow{2}{*}{130} \\
\hline & Layer 2 & 5.8 & 90 & \\
\hline \multirow{4}{*}{8} & Layer 1 & 5.5 & 70 & \multirow{4}{*}{135} \\
\hline & Layer 2 & 5.8 & 20 & \\
\hline & Layer 3 & 4.8 & 30 & \\
\hline & Layer 4 & 6 & 15 & \\
\hline \multirow{4}{*}{14} & Layer 1 & 5.6 & 70 & \multirow{4}{*}{135} \\
\hline & Layer 2 & 5.4 & 15 & \\
\hline & Layer 3 & 4.3 & 35 & \\
\hline & Layer 4 & 6 & 15 & \\
\hline \multirow{4}{*}{20} & Layer 1 & 5.7 & 70 & \multirow{4}{*}{135} \\
\hline & Layer 2 & 5.3 & 10 & \\
\hline & Layer 3 & 3.2 & 35 & \\
\hline & Layer 4 & 5.8 & 20 & \\
\hline
\end{tabular}

\begin{tabular}{|c|c|c|c|c|}
\hline \multicolumn{5}{|c|}{ (b) Injection of Mixture } \\
\hline $\begin{array}{l}\text { Time } \\
\text { (min) }\end{array}$ & Layer & $\begin{array}{l}S L D \pm 0.1 \\
\left(10^{-6} \AA^{-2}\right)\end{array}$ & $\begin{array}{c}\text { Thickness } \\
\pm 2(\AA)\end{array}$ & $\begin{array}{c}\text { Total } \\
\text { Thickness }\end{array}$ \\
\hline 3 & layer 1 & 5.7 & 30 & 30 \\
\hline \multirow{2}{*}{11} & layer 1 & 6.2 & 73 & \multirow{2}{*}{126} \\
\hline & layer 2 & 5.4 & 53 & \\
\hline \multirow{3}{*}{19} & Layer 1 & 5.8 & 50 & \multirow{3}{*}{124} \\
\hline & Layer 2 & 6.1 & 30 & \\
\hline & Layer 3 & 4.3 & 44 & \\
\hline \multirow{4}{*}{27} & Layer 1 & 5.9 & 80 & \multirow{4}{*}{123} \\
\hline & Layer 2 & 4.8 & 15 & \\
\hline & Layer 3 & 2.6 & 20 & \\
\hline & Layer 4 & 4.9 & 8 & \\
\hline \multirow{4}{*}{43} & Layer 1 & 5.9 & 70 & \multirow{4}{*}{129} \\
\hline & Layer 2 & 5.3 & 14 & \\
\hline & Layer 3 & 3.2 & 35 & \\
\hline & Layer 4 & 5.9 & 10 & \\
\hline \multirow{4}{*}{51} & Layer 1 & 4.8 & 70 & \multirow{4}{*}{135} \\
\hline & Layer 2 & 2.5 & 10 & \\
\hline & Layer 3 & 1.5 & 35 & \\
\hline & Layer 4 & 5.3 & 20 & \\
\hline
\end{tabular}

Table S3. Structural parameters obtained from the best fits to dynamic NR profiles measured for the co-adsorption of COE-3 at $0.01 \mathrm{mg} / \mathrm{ml}$ and PS80-7EO at $0.2 \mathrm{mg} / \mathrm{ml}$ in His $25 \mathrm{mM}$ buffer, $\mathrm{pH}$ 5.5. (a) PS80-7EO sample was injected after COE-3 adsorbed alone on the $\mathrm{SiO}_{2}$ surface and (b) PS80-7EO sample was pre-mixed with COE-3 and injected onto the bare $\mathrm{SiO}_{2}$ surface, all in $\mathrm{D}_{2} \mathrm{O}$ buffer.

\begin{tabular}{|c|cc|c|c|c|c|c|}
\hline Contrast & Head & $\tau_{\text {COE-3 }} / \boldsymbol{A}$ & $\phi_{\text {COE-3 }}$ & $\begin{array}{c}\Gamma_{\text {COE-3 }} \\
\text { mgm }^{-2}\end{array}$ & $\phi_{\text {surf }}$ & $\begin{array}{c}\Gamma_{\text {surf }} \text { in COE-3 } \\
m g m^{-2}\end{array}$ & $\begin{array}{c}S_{\text {Surf }} \Gamma_{\text {all }} \\
\text { mgm }^{-2}\end{array}$ \\
\hline $\mathrm{D}_{2} \mathrm{O}$ & $\mathrm{D}$ & $65 \pm 2$ & $0.23 \pm 0.03$ & $2.12 \pm 0.15$ & $0.07 \pm 0.01$ & $0.28 \pm 0.03$ & $3.15 \pm 0.04$ \\
\hline $\mathrm{CM} 2.58$ & $\mathrm{D}$ & $65 \pm 3$ & $0.23 \pm 0.04$ & $2.11 \pm 0.20$ & $0.07 \pm 0.02$ & $0.28 \pm 0.04$ & $3.13 \pm 0.05$ \\
\hline $\mathrm{D}_{2} \mathrm{O}$ & $\mathrm{H}$ & $61 \pm 2$ & $0.33 \pm 0.03$ & $2.88 \pm 0.15$ & $0.06 \pm 0.01$ & $0.02 \pm 0.01$ & $3.50 \pm 0.04$ \\
\hline $\mathrm{CM} 2.58$ & $\mathrm{H}$ & $61 \pm 3$ & $0.33 \pm 0.04$ & $2.86 \pm 0.20$ & $0.06 \pm 0.02$ & $0.02 \pm 0.01$ & $3.49 \pm 0.05$ \\
\hline
\end{tabular}

Table S4. Structural parameters obtained from the best fits in Rascal to the adsorbed mAb layers in NR profiles measured under 4 contrasts from co-adsorption of the mixed solution of COE-3 at $0.01 \mathrm{mg} / \mathrm{ml}$ and PS80-7EO at $0.2 \mathrm{mg} / \mathrm{ml}$ in His $25 \mathrm{mM}$ buffer, $\mathrm{pH} 5.5$. D and $\mathrm{H}$ denote PS80-7EO with deuterated and hydrogenated ethoxylate head, respectively. 
